\title{
El impacto del cambio de régimen sobre las políticas públicas: el caso de España*
}

\section{Richard Gunther **}

Los estudios empíricos en el campo de las políticas públicas desde un punto de vista comparado han tendido, desde el principio, a centrarse en una cuestión básica: importa la política? Desde el trabajo inicial de CuTricht (1965), numerosos estudios se han concentrado en un debate entre aquéllos que sostienen que los niveles de modernización socioeconómica y de riqueza son los principales determinantes del volumen y la estructura de los servicios del gobierno -más en concreto, los servicios sociales y los pagos de transferencias- de un lado, y aquéllos que, de otro, arguyen que los factores políticos tienen un impacto importante. Entre esas variables políticas cuyos impactos en las políticas públicas se han examinado más extensamente se encuentran el alcance de la competitividad partidista, las ideologías y las preferencias programáticas de los partidos politicos, y varios aspectos del régimen políico.

Mientras que muchos de esos temas al parecer se han resuelto en el curso de algo más de tres décadas de investigación, sin embargo, permanecen abiertas varias cuestiones relativas al impacto del régimen político, debido mayormente a la naturaleza compleja de la variable explicatoria clave: es extraordinariamente difícil, por ejemplo, captar en su totalidad las facetas multidimensionales y a menudo interactivas de los regímenes políticos (autoritario/democrático, civil/militar, izquierda/derecha, centralizado/descentralizado, presidencial/parlamentario) usando simples medidas cuantitativas o variables simuladas (variables dummy). Otro factor que dota de una cierta complicación a los estudios comparados transnacionales es que el número relativamente pequeño de casos de los cuales hay datos fiables disponibles, en combinación con el elevado nivel de multicolinearidad entre las variables explicativas, hace difícil desenredar y separar el impacto de los factores socioeconómicos de los políticos
- los países democráticos también tienden a ser ricos y desarrollados-, mientras que los regímenes autoritarios se encuentran más a menudo en sociedades económicamente atrasadas.

La transición a la democracia en España se nos presenta como una oportunidad valiosa y casi única para estudiar el impacto de las características del régimen político en las políticas públicas. Un cambio de régimen político dentro de un solo país hace posible controlar una amplia variedad de factores sociales y económicos, y de ahí aislar el impacto de las variables políticas. Una exploración de las políticas públicas españolas es especialmente fortuita (es decir, desde un punto de vista puramente metodológico), en la medida en que la fase más rápida del desarrollo económico del país había tenido lugar con anterioridad al colapso del sistema autoritario y el surgimiento de las nuevas instituciones democráticas. El crecimiento económico real entre 1960 y 1975 alcanzó un promedio de $6.8 \%$ al año, y a principios de los 70 España había sobrepasado ciaramente el umbral del desarrollo socioeconómico considerado comúnmente como un prerrequisito para el desarrollo de los Estados de bienestar avanzados. En contraste con la década anterior, desde 1975 hasta 1985 la economía espanola en conjunto estuvo paralizada, con una tasa de crecimiento real de sólo un 1.7\% (AiCAIDE, 1994: 57). Estas circunstancias económicas estrictamente facilitan nuestros esfuerzos para medir los efectos del cambio político que comenzó en 1975, puesto que algunos incrementos posteriores en los resultados de las políticas públicas no pudieron explicarse como meros productos de la creciente opulencia. En efécto, la variable desarrollo económico puede permanecer constante. Por el contrario, las masivas transformaciones políticas (incluidos la sustitución de la dictadura por la democracia, la legalización de los sindicatos y los partidos poli- 
ticos competitivos, y la dotación de poder a los grupos sociales anteriormente excluidos) tuvieron lugar justamente cuando la economía iba entrando en un largo período de estancamiento. Si la política importa, entonces esperaríamos descubrir que la democratización (en un período de estancamiento económico) iría acompañada de una expansión de estos programas. Pero si el argumento de WILENSKY es correcto (1975: 13) por ejemplo, que el crecimiento económico y sus consecuencias demográficas y burocráticas son los determinantes reales de estas políticas sociales, mientras que los factores políticos tales como las ideologías "colectivistas" versus individualistas, o incluso los sistemas políticos «democráticos" versus «totalitarios" ... resultan casi inútiles para explicar los orígenes y el desarrollo general del Estado de bienestar entonces esperaríamos descubrir que el período más rápido de expansión de las políticas públicas sociales habría correspondido con el boom económico de los 60 y principios de los 70 , y que la democratización posterior habría tenido un impacto poco perceptible.

Este estudio comparado longitudinal se facilita por la disponibilidad de entrevistas paralelas en profundidad con las élites claves en la toma de decisiones bajo los dos regímenes autoritario y democrático en España ', lo cual hace posible ir más allá de las inferencias basadas únicamente en los datos cuantitativos para interpretar las opciones de políticas públicas sobre la base de las percepciones, objetivos y cálculos de los decisores clave bajo ambos regímenes.

\section{Las políticas públicas bajo Franco}

Durante los años finales del régimen de Franco, España era, en muchos aspectos, sorprendentemente diferente de otros Estados industrializados occidentales en lo que respecta a varios resultados de políticas públicas importantes. En 1975, por ejemplo, su nivel global de imposición fiscal era el más bajo de cualquier país en la Europa occidental, y entre todos los Estados miembros de la OCDE, España quedaba la última a excepción de Turquía, mucho menos desarrollada económicamente. Como puede observarse en la Tabla 1, el 19.5\% de Producto Interior Bruto que fluctuó a todos los niveles de gobierno, en España estaba sustancialmente muy por debajo de la media de la OCDE del $32.7 \%$

Como resultado del pequeño volumen de ingresos que fluían al Estado durante los últimos años de la era franquista, en combinación con la adopción de los presupuestos estatales equilibrados, el Estado español quedaba muy por detrás de otros gobiernos europeos occidentales con respecto a la provisión de servicios básicos. En 1975, sólo un 9.9\% del PIB de España se dedicó a la provisión de servicios sociales, comparado con el promedio de la Comunidad Europea del 24\% (Maravall, 1993: 84). De hecho, algunos servicios básicos se hallaban a niveles del .Tercer Mundo. En 1964, por ejemplo, los gastos del Estado español en educación eran menos de un tercio (como porcentaje del PIB) de los niveles de gasto en educación en la Alemania occidental, Francia y Austria, e inferiores a la cuarta parte de los del Reino Unido, Países Bajos y Bélgica (Ministerio de Educación y Ciencia, 1969: 174). Los porcentajes españoles de matriculación en educación superior en 1967 eran tan bajos como los del cuartil más pobre de los 64 países estudiados por Harold WILENSKY. España, por tanto, se situaba junto a países tales como el Volta Superior, India, Togo y Paraguay ${ }^{2}$. Y los datos de 1965 reunidos por TAYLOR y HUDSON (1972: 32) mostraron que los niveles de gasto del Gobierno español en educación (como porcentaje de su PNB) le equiparaban a Angola, en la posición 122 de 131 países incluidos en el estudio. Existía en esta época un considerable sector privado de educación (principalmente religiosa). Sin embargo, mientras los hijos de las familias de clase media que podían permitirse el pago de las matrículas del sector privado tenían un acceso mayor a la educación de lo que las estadísticas del gasto del sector público arriba mencionado podrían sugerir, la ausencia de la educación elemental gratuita para todos los niños españoles continuó siendo un rasgo distintivo durante todo el régimen franquista. Una reforma significativa del sistema de educación se inició tras la promulgación de la Ley General de Educación en 1970, pero a pesar de esta iniciativa de políica educativa, el sistema educativo de España permaneció subdesarrollado y drásticamente infrafinanciado. En tomo a 1973, los gastos en educación habían ascendido a un $2.1 \%$ del PIB (desde el $1.5 \%$ de los nueve años anteriores), pero estaba todavía muy por detrás del gasto en educación en otras sociedades europeas occidentales ${ }^{3}$. En 1977, el Ministerio de Educación español era todavía incapaz de proporcionar una educación elemental gratuita a todos los niños.

Había otros ejemplos sorprendentes de los bajos niveles del gasto del Presupuesto del Estado bajo el régimen franquista, tales como el gasto en defensa nacional. A pesar de los antecedentes militares del Generalísimo Franco y el papel central jugado por el ejército en la fundación del régimen, en 1973 el Gobiemo español gastaba menos (en porcentaje del PIB) en defensa que cualquier país europeo excepto Luxemburgo (GUNTHER, 1980: 49). La infraestructura física del país era también por desgracia deficiente. De hecho, no fue hasta los 80 cuando la capital, Madrid, se conectó con el resto de Europa por una autopista con varios carriles.

En alguna medida, estos bajos niveles de gasto y servicios del Gobiemo pueden atribuirse a los lentos efectos de una tardía industrialización. Pero este argumento del slegado histórico. socioeconómico proporciona, en el mejor de los casos, sólo una explicación parcial de estas anomalías. A mitad de los 70, España había llegado a ser la décima potencia industrial 
Tabla 1

Ingresos fiscales como porcentaje del Producto

Interior Bruto, 1975

\section{Pais}

Nonega

Suecia

Países Bajos

Luxemburgo

Bélgica

Dinamarca

41.4

Austria

Finlandia

Francia

Alemania occidental

Reino Unido

Media de la OCDE

Canadá

Nueva Zelanda

Irlanda

Suiza

Estados Unidos

Australia

Italia

Grecia

Portugal

Japón

España

Turquía

16.0

Fuente: Organización para la Cooperación y el Desarrollo Económico, Estadisticas de Ingresos de los Paises Miembros de ha OCDE, 1965-1994. Paris: OCDE, 1995: 73.

del mundo (SCHwaRTZ, 1976: 86), y sus ingresos per capita en $1973(\$ 6,945)$ en la Paridad del Poder de Compra 1985 dólares americanos) la colocaban entre los 30 países más ricos del mundo, a la cabeza de Irlanda $(\$ 5,601)$, Grecia $(\$ 5,218)$,
Portugal $(\$ 4,474)$, Chile $(\$ 3,622)$ y Turquía $(\$ 2,472)$ y estaba muy por delante de los países del Tercer Mundo tales como Zaire (\$688), India (\$786) e Indonesia $(\$ 823)^{4}$. Sin embargo, como puede verse en la Tabla 1, su nivel global de imposición fiscal en 1975 (19.5\% del PIB) estaba significativamente por debajo de aquellos países más pobres tales como Irlanda (30.0\%), Grecia (22.5\%) y Portugal (24.7\%). Y cuando se eliminan de este total los impuestos por la seguridad social, aparece una anomalía todavía más sorprendente: entre 1965 y 1975 , todos estos ingresos fiscales realmente descendieron como parte del PIB de España, del 10.5 al 10.3\% Esto no sólo representa una desviación dramática de ‘la ley de Wagner. (WAGNER, 1892) sino que también significa que España estaba situándose de hecho muy por detrás del resto del mundo industrializado ", al mismo tiempo que tenía una de las tasas más rápidas de crecimiento económico en la Europa occidental. De forma similar, el gasto en muchos servicios no estaba creciendo (en términos reales) siquiera incrementalmente, y estaba cayendo incluso muy por detrás de la media europea occidental. Dadas las altas tasas de crecimiento económico en esta época, y la rápida aproximación de España a los niveles europeos occidentales de desarrollo socioeconómico y bienestar, debemos concluir que estas anomalías en la imposición fiscal y el gasto no pueden explicarse adecuadamente por la hipótesis socioeconómica descrita arriba.

La causa inmediata de estas aberraciones era un sistema fiscal que generaba un volumen insuficiente de ingresos. Este sistema fue criticado duramente a comienzos de los 70 , no sólo porque era incapaz de conseguir los ingresos suficientes, sino también porque era enormemente injusto en su distribución de la carga impositiva. La estructura tributaria era extremadamente regresiva, derivándose algo más del $73 \%$ de sus ingresos tributarios totales (en 1970) de impuestos indirectos y contribuciones a la seguridad social (OCDE, 1995: 79 y 84). Un estudio de la distribución real de la carga impositiva bajo este sistema reveló que los españoles con rentas elevadas pagaban un $50 \%$ menos impuestos, como porcentaje de sus ingresos totales, que aquellos que se encontraban en los niveles de renta más pobres ( $\mathrm{PE}$ RONA, 1972: 475-6). Su estructura arcaica y compleja, unida a un número insuficiente de inspectores fiscales, también lo hizo altamente susceptible de evasión fiscal. Por tanto, una cuestión clave en nuestra búsqueda de una explicación de las políicas aberrantes de gasto e imposición es ¿por qué se mantuvo este sistema, sin reformar, hasta después de la muerte de Franco en 1975?

La única excepción parcial a este modelo de gasto extraordinariamente bajo era el sistema de la Seguridad Social, que administraba las pensiones de jubilación (las primeras establecidas en 1919), los servicios de maternidad (1926), el seguro de accidentes laborales (1938), el seguro de invalidez (1939) y el seguro médico (1942). Estaba fuera del Presupuesto estatal, y completamente eximido del control del Mi- 
nisterio de Hacienda. Basado casi exclusivamente en las contribuciones de los trabajadores y empresarios, no se vio constreñido por las limitaciones políticas en los ingresos tributarios que tan severamente limitaron el crecimiento del gasto del Presupuesto del Estado. En consecuencia, entre 1965 y 1975 el flujo total de ingresos al sistema de la Seguridad Social se incrementó más del doble como parte del PIB, de un $4.2 \%$ a un $9.3 \%$ De acuerdo con una explicación socioeconómican del gasto del bienestar, los gastos en todos los programas de la Seguridad Social se incrementaron de un $2.7 \%$ del PIB en 1964 a un punto entre un $10.3 \%$ (INP, 1976) y un $12.1 \%$ (Velarde, 1990: 109) en 1975, y al final de ese período casi un $81 \%$ de la población tenía cobertura del sistema del servicio de salud (Guilién, 1992: 126). Incluso así, España continuó estando retrasada significativamente, por detrás de otros países europeos occidentales a este respecto. En 1975, por ejemplo, se estaba gastando el 4.3\% del PIB en pensiones de jubilación (comparado con una media de la OCDE del 7.6\%) y su nivel global de gasto en todos los programas en ese año (12.1\%) también estaba sustancialmente por debajo de la media de la OCDE (20.1\% [GuILLÉn, 1992: 127-8]). La naturaleza del sistema basado en el empleo también significaba que la cobertura era desigual e incompleta. Como ha descrito Gullén (1992: 126), era un sistema de bienestar organizado a lo largo de líneas corporativistas, con disimilitudes significativas entre varias categorias profesionales y una dirección altamente fragmentadan. La desviación mayor respecto de la pauta europea occidental, sin embargo, era el volumen extraordinariamente pequeño de transferencias desde el presupuesto estatal para ayudar a financiar el sistema de la Seguridad Social: en 1975, las transferencias estatales ascendieron sólo a un $0.43 \%$ del PNB - la media por país- de la OCDE tenía un nivel de transferencias del presupuesto estatal a la Seguridad Social que era 28 veces mayor (GUILLÉN, 1992: 128) ${ }^{6}$.

Los resultados de un estudio detallado sobre los procesos a través de los cuales se formularon los Presupuestos del Estado y los planes de desarrollo económico, y se seleccionaron los proyectos específicos de inversión en el período del tardo-franquismo indican que estos resultados anómalos eran producto de las caracteństicas inusuales de los propios procesos de toma de decisión económica del Estado, que eran, a su vez, consecuencia sistemática de los rasgos institucionalizados del régimen autoritario de Franco ${ }^{7}$.

\section{Los procesos de toma de decisión bajo el franquismo}

Los procesos de toma de decisiones económicas de la Administración del Estado durante la década final del régimen de
Franco revelaron varias características que eran las más extraordinarias, si no únicas entre los gobiernos de los países industrializados occidentales. La primera alude a la manera en que se agregaban los intereses y se establecían las prioridades de gasto de primer orden ${ }^{8}$. En los procesos presupuestarios de otros países occidentales, las figuras políticas centrales (presidentes, primeros ministros, consejos de ministros, comités del gabinete y a veces los partidos en el gobierno), desempeñan roles dominantes en el establecimiento de las prioridades básicas del gasto ${ }^{9}$. Desde un punto de vista comparado, en la España franquista las personas e instituciones situadas en el centro del aparato del Estado ni establecieron prioridades de gasto sistemáticas ni desempeñaron un rol significativo en la coordinación de las políticas públicas. Las prioridades de orden superior tanto del presupuesto estatal anual y del Plan de Desarrollo cuatrienal, en cambio, surgieron en gran medida como producto de las negociaciones bilaterales privadas entre los Ministros que efectuaban el gasto, por una parte, y los Ministros de Hacienda y Planificación del Desarrollo, respectivamente, por otra. El Consejo de Ministros nunca intentó ordenar sistemáticamente las prioridades presupuestarias del Estado; su rol se limitó efectivamente a ratificar de forma superficial las decisiones tomadas en el curso de las negociaciones bilaterales anteriores. Franco y su íntimo colaborador (y en 1973, Primer Ministro) Luis Carrero Blanco rara vez intervinieron en estos procesos de toma de decisiones económicas, y nunca intentaron establecer prioridades globales de gasto para el Estado.

Los grupos formales o informales fuera de la Administración del Estado no desempeñaron un rol significativo en estos procesos de toma de decisiones. Las Cortes (cuasi-Parlamento cuasi-corporativo del régimen autoritario) no modificaron la ley sobre el presupuesto del Gobierno ni la propuesta del Plan de Desarrollo. El Movimiento Nacional (único partido oficial del régimen) había llegado a ser a comienzos de los 70 un armatoste burocrático sin vida, y los responsables tanto en los ministerios de gastos y las oficinas de presupuesto y planificación dijeron unánimemente que la ignoraban. Sin embargo, los intereses del sector privado se articularon incesantemente con respecto a la distribución intersectorial de los recursos realizada por los Ministerios que efectuaban el gasto. En la selección de los emplazamientos para los proyectos de inversión estatal, solicitudes para los pagos del subsidio a firmas privadas, determinar la distribución geográfica de los presupuestos ... y tomar otras decisiones económicas que afectan a los intereses desagregados, los funcionarios del Ministerio que efectuaba el gasto eran bombardeados con llamadas particulares de individuos que hablaban a favor de los intereses del sector privado. Pero los grupos o representantes del sector privado no tuvieron un impacto significativo en las prioridades de gasto de orden superior del Gobierno, según la opinión unánime de todos los entrevistados en 1974 y 1975. Los funcionarios del Ministerio que efectuaba el gasto 
nunca intentaron movilizar a los grupos clientelares como medio de influir en las decisiones del Ministerio de Hacienda, y ningún funcionario de dicho Ministerio informó de cualquier contacto, cualquiera que fuese, con personas de fuera de la Administración del Estado o con representantes del Movimiento Nacional durante la formulación del presupuesto. Ni los individuos que representaban los intereses del sector privado, ni el Movimiento Nacional ni los sindicatos (las organizaciones sindicales verticales corporativas del régimen) tuvieron un impacto significativo en las prioridades incorporadas en el Plan. Finalmente, los ciudadanos españoles de a pie carecieron por completo de mecanismos institucionales para la articulación y agregación de sus demandas. Sólo las demostraciones esporádicas en forma de estallidos de protesta (tales como los disturbios laborales de finales de los 50 y principios de los 60 y las movilizaciones de estudiantes de finales de los 60) influyeron efectivamente en las decisiones gubernamentales del gasto. Estas movilizaciones de las masas, sin embargo, fueron en gran medida espasmódicas y limitadas en su alcance, y las respuestas que obtuvieron de las políticas públicas tuvieron generalmente una vida corta ${ }^{10}$ y a veces contrarias a las demandas de los que protestaban (p. ej., cuando el Estado respondía con represión antes que con concesiones). En resumen, las decisiones económicas de orden superior se tomaron en ausencia de las demandas "agregadas" de los grupos de fuera de la Administración del Estado. Había, sin embargo, una gran articulación. de intereses de una clase muy especial: era especial tanto con respecto al estrecho ámbito de intereses relevantes como con respecto a que el acceso de los decisores se restringía generalmente a aquellos que representaban al gobierno local o a las organizaciones corporativas dentro del régimen y en gran medida a los individuos de status socioeconómico alto que disfrutaban de enchufes (contactos personales) con las figuras poderosas del régimen.

Una característica final de estos procesos de toma de decisión era que los ministros que efectuaban el gasto disfrutaban de un extraordinario grado de autonomía para establecer las políticas que se incluian dentro de sus respectivas jurisdicciones departamentales, y para establecer prioridades de gasto intrasectoriales. Sólo en muy raras ocasiones el Consejo de Ministros, Franco, o incluso los Ministros de Hacienda y Planificación intervinieron para alterar las políticas de gasto intradepartamentales.

Sin embargo, esto de ninguna manera significa que Franco y sus colaboradores más próximos no tuvieran influencia sobre las decisiones del gasto público. Su principal influencia sobre el presupuesto fue ejercida indirectamente, primero a través del reclutamiento de los ministros del Gobierno. Las políticas fiscales conservadoras casi se garantizaban con el reclutamiento para el cargo sólo de personas con valores políicos conservadores y pertenencia a clases sociales alta y media-alta. La existencia de un acuerdo casi consensual de las fronteras que rodeaban las opciones aceptables de políticas públicas hicieron innecesario que Franco o Carrero intervinieran en los procesos de toma de decisiones económicas la mayor parte del tiempo. En vez de eso, los Ministros de Hacienda y Planificación establecieron las prioridades de gasto (a través de negociaciones bilaterales privadas, con los diferentes ministros que efectuaban el gasto) dentro de lo que constituía una rona de indiferencia para Franco y Carrero.

Ciertas clases de temas, sin embargo, preocupaban mucho a Franco y, por tanto, casi constituían áreas de política reservada. Éstos incluían (1) asuntos de orden público, (2) relaciones Iglesia/Estado, (3) las fuerzas armadas, y (4) el carácter de las instituciones básicas del régimen y, en particular, la selección de su sucesor. Cuando uno de estos temas llegaba a estar íntimamente vinculado con las decisiones presupuestarias y de planificación, Franco y Carrero abandonarían su normal pasividad e intervendrían activamente en el proceso de toma de decisiones. Cuando estallaron las masivas demostraciones tras el proceso de Burgos en 1970 y se reavivó el interés de la élite franquista en el gasto militar y policial, Franco y Carrero concluyeron rápidamente que las constantes reducciones del Ministerio de $\mathrm{Ha}$ cienda en las partidas presupuestarias destinadas a las fuerzas armadas y de seguridad habían socavado la capacidad del Estado para reprimir la disensión. Lo que se había considerado anteriormente como meros asuntos presupuestarios que se incluían dentro de una zona de indiferencia respecto de las políticas públicas atrajeron de repente la atención de la élite franquista. Su respuesta fue promulgar la Ley de Defensa Nacional (1971), que incrementó la partida presupuestaria destinada a los gastos de defensa y seguridad, y suprimió los gastos militares del proceso presupuestario anual junto con la concesión a los Ministerios militares de sumas específicas en un período de diez años.

El ejemplo de mayor alcance de la intervención de Franco en el proceso presupuestario incluía unas propuestas formuladas por el Ministerio de Hacienda en 1973, que habrían reformado sustancialmente el sistema de imposición fiscal distribuyendo la carga impositiva -más justamente entre las clases sociales, habría cerrado las vías de escape existentes de las que se aprovecharan fundamentalmente los españoles de rentas altas, y habría incrementado el flujo de ingresos al Estado, ayudando así a corregir algunas deficiencias serias en la provisión de los servicios públicos básicos. El mismo día en que se presentó la propuesta al Consejo de Ministros en junio de 1973, Franco destituyó a todo el Gobierno y clasificó el informe del Ministro de Hacienda sobre el sistema de imposición como documento secreto, ostensiblemente sobre la base de que estaba todavía "pendiente de una decisión del Consejo de Ministros". Los funcionarios del Gobierno entrevistados en 1974 y 1975 interpreta- 
ron de distinta forma esta intervención, como motivada por la creencia de que las reformas propuestas podrían desagradar a los profesionales y clases medias cuyo apoyo al régimen (según argumentaron RICHARDSON y FERNÁNDEZ [1973: 1]) había .sido comprado con tipos impositivos bajosn; que la propuesta era simplemente demasiado socialista. $y$, por tanto, incongruente con los valores conservadores de Franco y la orientación política anti-izquierdista; y/o que esta propuesta podría haber generado conflicto o al menos insatisfacción dentro o entre aquellos grupos que formaban la coalición franquista. Pero las consecuencias de esta intervención no fueron ambiguas: el cambio ministerial de junio de 1973 y la supresión del informe de cuatro volúmenes del Ministerio de Hacienda acabó efectivamente con todas las expectativas de reforma fiscal hasta el término del régimen franquista, e impuso severas restricciones a la evolución de todo el sector público.

Yo mantengo que estos rasgos distintivos de los procesos de las políticas públicas españolas y sus resultados son consecuencias sistemáticas de rasgos importantes del régimen autoritario franquista. El personalismo, la fragmentación departamental de las jurisdicciones de políticas públicas y los importantes roles de los Ministros de Hacienda no son de ninguna manera exclusivos de la España franquista; pero estos rasgos alcanzaron una importancia excesiva bajo ese régimen debido a la ausencia de otro tipo de factores relevantes para la formulación de las políticas públicas que se encuentran universalmente en los sistemas-democráticos. Puede considerarse que la toma de decisiones económicas bajo este régimen autoritario, de alguna forma, ha tenido lugar paradójicamente dentro de un relativo vacío de poder que era resultado directo de los cambios básicos en las políticas públicas españolas que se habían acometido al fundar el régimen.

El impulso básico de los esfuerzos de Franco para restructurar el Estado español y regular la sociedad incluía la supresión del conflicto político. Todas las organizaciones dedicadas a expresar el conflicto social y político (partidos políticos y sindicatos) fueron suprimidas vigorosamente hasta el día de la muerte de Franco. El régimen autoritario no formuló ninguna ideología que pudiera haber guiado la formulación de las políticas públicas, y no existió ningún aparato de partido poderoso que podría haber sido movilizado en el curso de las disputas de políticas públicas. La autoridad última en este sistema iba a conferirse a un solo individuo - el mismo Franco- y no fluía desde abajo, como en los sistemas basados en la responsabilidad electoral y el sufragio universal. Los ciudadanos carecían de canales institucionalizados efectivos a través de los cuales articular sus apremiantes demandas de políticas públicas. Por tanto, la mayoría de las prioridades presupuestarias (que se incluían en la :zona de indiferencia. de Franco, puesto que él no estaba interesado en los temas económicos) era fijada por un puñado de individuos dentro de un relativo vacío de poder, desprovisto de los recursos coercitivos que pueden movilizarse en los sistemas democráticos por las disputas sobre políticas públicas.

En ausencia de recursos políticos como éstos, dos fuentes de poder y autoridad alcanzaron una importancia anormal en estos procesos de toma de decisiones: la jerarquía ministerial, y las dinámicas sociales y psicológicas de interacción personal. La jerarquía ministerial era una fuente de autoridad sobre la cual todos los titulares de los departamentos podrían estar de acuerdo. En consecuencia, la autoridad para tomar decisiones de política económica y social se distribuía estrictamente de acuerdo con el Derecho administrativo español, casi exclusivamente sobre la base de la jerarquía departamental. Esta distribución de la autoridad altamente compartimentalizada en la toma de decisión significaba que se consideraba que cada ministro tenía una autoridad completa para establecer aquellas políticas que se incluían dentro de la competencia de su departamento. Cuestiones relativas a la vivienda pública, por ejemplo, se consideraban asuntos reservados al Ministro de la Vivienda, no como una parte integral de las políticas sociales del Gobierno (lo cual podría haber implicado una intervención más activa del Consejo de Ministros). Esto también significaba que los ministros eran responsables como individuos del éxito o fracaso de las políticas adoptadas por sus departamentos, mientras que el Consejo de Ministros tenía poco sentido de la responsabilidad colectiva por los diversos sectores de las políticas de gasto del Estado. En consecuencia, el Gobierno no jugó un papel, como cuerpo colectivo, en la coordinación de las prioridades interdepartamentales de aquellas políticas de gasto, haciendo recaer la responsabilidad por la coordinación de la política económica sobre un ministro cuya jurisdicción se solapaba con las de otros departamentos - el Ministro de Hacienda (o, en el proceso de planificación, de la Planificación del Desarrollo) ${ }^{11}$. La formulación del presupuesto del Ministerio de Agricultura, por ejemplo, se percibía en parte como un asunto de política agrícola (recayendo, así, bajo la jurisdicción del Ministro de Agricultura) y en parte, como un asunto de finanzas públicas (por tanto, bajo la jurisdicción del Ministro de Hacienda). En consecuencia, el presupuesto del Ministerio de Agricultura se establecía en el curso de negociaciones bilaterales privadas entre el Ministro de Hacienda (y su equipo departamental de apoyo) y el Ministro de Agricultura (y sus ayudantes y asociados). En efecto, todo el presupuesto del Estado se fijaba, departamento por departamento, de esta forma fragmentada.

Un corolario de esta elevada concentración de la autoridad en la toma de decisiones en manos de los Ministros de Hacienda y Planificación era que las preferencias personales de esos dos individuos sobre políticas públicas tenían mayor influencia en la configuración de las políticas del gasto en España de la que uno podría esperar de los Ministros de Hacienda en otros 
sistemas presupuestarios, dentro de los cuales tales preferencias personales están a menudo subordinadas a fuertes restricciones políticas. El personalismo y el particularismo también se reforzaron bajo este sistema en la medida en que eran factores clave en las dinámicas de persuasión social y psicológica, los cuales, puesto que la coerción fue en gran medida imposible dentro del vacío de poder intemo del régimen, continuaron siendo el principal medio por el cual un Ministro podría influir en otro. La probabilidad que tenía un departamento que efectuaba el gasto de recibir un incremento del presupuesto dependía enormemente de la habilidad negociadora de su Ministro y su conocimiento y experiencia personal. La naturaleza de la relación personal entre el Ministro que efectuaba el gasto y el Ministro de Hacienda o Planificación también afectó fuertemente a la prioridad última de los programas de su sector: permaneciendo igual el resto de cosas, un Ministro de Hacienda o Planificación respondería más diligentemente a las peticiones de un Ministro que efectuaba el gasto de la misma efamilia política o facción, con los mismos valores básicos, de lo que respondería a las peticiones de un Ministro con una perspectiva significativamente diferente o que le disgustase. Sin lugar a dudas, estas dinámicas personales están presentes en los procesos presupuestarios y de planificación de todos los países, pero asumieron una importancia desproporcional en la España franquista a causa de la ausencia de demandas agregadas de otros actores y procesos que ejerciesen presión sobre los Ministros de Hacienda y Planificación.

En los sistemas democráticos, por ejemplo, la función de agregación de intereses aumenta mediante la competición electoral. Las elecciones implican directamente la formación de coaliciones, ya sea antes de la elección (como en los Estados Unidos) como después de la elección (como en los sistemas parlamentarios multipartidistas), y la formación de coaliciones es, por su propia naturaleza, un proceso de agregación de intereses. En la formulación de campañas electorales, compitiendo por el apoyo electoral o parlamentario, los políticos agregan los intereses de una gama de grupos sociales siempre más amplia. Estos incentivos estaban ausentes bajo el régimen franquista. Los ministros eran responsables no frente a una masa electoral, con intereses dispares y objetivos opuestos, sino ante un único individuo al que no le importaban la mayoría de las políticas económicas la mayor parte del tiempo.

La restricción última sobre las políticas del gasto público y fiscal con Franco era el carácter autoritario del régimen mismo especialmente la negación del sufragio universal y la supresión del conflicto político institucionalizado. Hace tiempo, V.O. KFY especuló acerca del impacto de la ausencia del conflicto entre partidos competitivos sobre los procesos de políticas públicas y distribución de la renta:

-El gran objetivo de los ricos es la obstrucción, al menos de los ricos que adoptan sólo una perspectiva a corto plazo. La organiza- ción no siempre es necesaria para obstruir; es esencial, sin embargo, para la promoción de un programa firme en favor de los desposeídos ... Desde siempre los desposeídos pierden en una política desorganizada. Ellos no tienen mecanismo alguno a través del cual actuar, y sus deseos encuentran expresión en rebeliones intermitentes ... Las escalas del conflicto entre los que tienen y los que no tienen se han inclinado por la exclusión de un sector sustancial de la población desposeída ... de la paricipación efectiva en política. (KEY, 1949: 307).

Los procesos de políticas públicas y los resultados en la España franquista son congruentes con la hipótesis de KEY: los patrocinadores de la reforma eran incapaces de organizar el apoyo público para sus propuestas, y los ministros que habían llegado a estar convencidos de la necesidad de cambios sustanciales en las políticas públicas carecían de los recursos coercitivos institucionalizados necesarios para conseguir el apoyo de sus colegas de gabinete. Y lo que es más importante, la articulación de las demandas de la población en general -a favor de más y mejores servicios gubernamentales, o de un sistema de imposición más justo- fue reprimida por la propia naturaleza del régimen mismo. Los impuestos regresivos y las políticas de gasto conservadoras eran los productos obvios del reclutamiento para los puestos claves de gobierno únicamente de individuos de procedencia socioeconómica alta y con valores conservadores, junto con la ausencia de canales para la articulación de las demandas de fuera de la Administración del Estado, sin mencionar la represión de las movilizaciones de masas en apoyo de las demandas redistributivas por parte de los estratos menos favorecidos. En resumen, muchos de los rasgos aberrantes de las polítjcas públicas españolas desde comienzos hasta mediados de los 70 eran consecuencia del autoritarismo del régimen, en interacción con su clase alta y media-alta base del apoyo, y su "mentalidad. conservadora. Sólo el sistema de la Seguridad Social (fuera de la Administración del Estado, con su propia fuente de ingresos e influenciada más fuertemente por una tradición de populismo falangista) en cierto modo se desvió de este modelo global.

\section{Las políticas públicas españolas en la era democrática}

De acuerdo con esta explicación centrada en el régimen político de los rasgos aberrantes de los resultados de las políticas públicas españolas y los procesos de toma de decisiones al final de la era franquista, los cambios significativos empezaron a tener lugar tras los resultados inmediatos de las primeras elecciones democráticas en junio de 1977. A finales de los 80 y principios de los 90, España se 
había aproximado a otras democracias europeas occidentales en lo relativo a los contornos básicos de sus políticas públicas.

Antes de entrar en este análisis, es importante apuntar que el desmantelamiento del régimen político no incluyó una purga de la Administración del Estado. No hubo un cambio extraordinariamente amplio de personal dentro de los ministerios, $e$ incluso los modelos de carrera profesional de aquellos individuos que ocuparon posiciones "políticas" dentro de la mayor parte de los departamentos de la Administración del Estado (por ejemplo, directores generales y subsecretarios) fueron en gran medida continuados. Esto es en parte producto del hecho de que a mitad de los 70 los criterios tecnocráticos y apolíticos habían llegado a dominar los procesos de reclutamiento de la Administración del Estado, y el papel del Movimiento Nacional en el reclutamiento de la élite había llegado a ser virtualmente nulo. Además, la burocracia del Estado no estaba saturada de personal: de hecho, la Administración del Estado estaba entre las más pequeñas (en términos de funcionarios públicos como porcentaje del total de la población) en Europa occidental (BELTRÁN, 1990: 349; y GUNTHER, 1980: 85). Por tanto, no había un telón de fondo que apoyase una purga de la Administración del Estado sobre la base de que estaba inflada y era ineficiente, o dotada de funcionarios politicos mediocres e incompetentes. Una consecuencia positiva de esta continuidad en el personal administrativo es que no hubo una pérdida temporal del control sobre el aparato del Estado durante la transición. Se mantenían niveles razonables de eficiencia, y no hubo un caos como el experimentado en la vecina Portugal, aparte del colapso de la autoridad del Estado que han experimentado algunos países del anterior Bloque del Este en los 90.

\section{Los resultados de las políticas públicas en la España democrática}

En el análisis siguiente, haremos una distinción entre cuatro períodos diferentes que reflejan decididamente las diferentes circunstancias de la toma de decisiones. El primero empezó con las elecciones de junio de 1977 y finalizó en la primavera de 1979. Durante este período, el Primer Ministro de un Gobierno minoritario formado por un único partido, de centro derecha, la UCD (Unión de Centro Democrático), Adolfo Suárez, negoció con los otros dos partidos mayoritarios una nueva Constitución, completando de ese modo ampliamente la transición a un régimen democrático. La segunda fase era aquélla que aconteció entre el fin de la "política de consenso" en 1979 y la elección de un Gobierno socialista (PSOE) a finales de 1982. Esta fase estuvo marcada por el disenso y duros encontronazos (que enfrentaron especialmente al PSOE y a la UCD, y a una facción del partido gobernante que se desintegraba contra otra). La tercera fase comenzó con la elección de un Gobierno mayoritario del PSOE a finales de 1982, y terminó con la pérdida de la mayoría parlamentaria absoluta en 1989. Algunas características definitorias de la cuarta fase (que terminó en 1996, tras la pérdida por el PSOE de las elecciones de marzo) comenzaron a surgir en 1989, pero llegaron a ser más patentes tras la formación de un Gobierno minoritario de un solo partido en 1993. Como veremos, importantes aspectos de los procesos de toma de decisiones variaron de una fase a otra, con algún impacto en los resultados de las políticas públicas del Estado. Estas cuatro fases se diferenciaban del pasado franquista en muchos aspectos.

Un cambio mayor en los resultados de las políticas públicas ocurrió en 1977 inmediatamente después de la primera elección democrática. Como hemos visto, la pieza clave de las prácticas presupuestarias conservadoras de la era franquista era el sistema fiscal, arcaico, regresivo y propenso a la evasión, y la imposibilidad política de reformar sustancialmente ese sistema. Una vez que el principal obstáculo político para la reforma fiscal (el propio Franco) desapareció de la escena y llegó al poder un Gobierno democráticamente elegido, la reforma de ese sistema se llevó a cabo inmediatamente. El primer Gobierno de la UCD de Suárez aprobó (inicialmente a través de la promulgación de un Decreto de emergencia) un paquete sustancial de reformas del sistema fiscal que eliminaba las cuentas bancarias secretas, aumentaba las sanciones legales por evasión fiscal, extendía el servicio de auditoría del Ministerio de Hacienda, imponía una carga mayor al impuesto sobre la renta, e introducía un impuesto sobre el patrimonio neto. Estos cambios no tuvieron el propósito de tener un impacto revolucionario sobre el nivel de imposición, pero incrementaron significativamente el flujo de ingresos al Estado: entre 1975 y 1982, todos los ingresos impositivos (incluidos las contribuciones a la Seguridad Social) aumentaron de un $19.5 \%$ a un $25.6 \%$ del Producto Interior Bruto (OCDE, 1995).

En combinación con el abandono de una segunda restricción mayor sobre el gasto del Gobierno que era un componente integral de la política fiscal en los últimos años de Franco - la adopción invariable de presupuestos equilibrados (ver GUNTHER, 1980: 78-110)— esto permitió considerar una expansión masiva de los gastos del Gobierno. Entre 1975 y 1982, el nivel total del gasto del Gobiemo aumentó de un $24.9 \%$ a un 38.2\% del PIB (ALCAIDE, 1994: 72). Esto representa una aceleración significativa en el crecimiento del gasto público: entre 1960 y 1974, los gastos públicos se habían incrementado en un porcentaje de sólo un $0.2 \%$ del PIB por año; en los ocho años siguientes, este porcentaje de expansión fue casi diez veces más rápido. Puesto que los ingresos impositivos aumentaron a un ritmo mucho más lento de lo que lo hizo el gasto del Gobierno, esto significó que una porción sustancial de los gastos del Go- 
bierno fue financiada a través del préstamo y la emisión de deuda pública (que alcanzó un 4.6\% del PIB en 1983 [Rodrícuez CABRERO, 1994: 1447). El gasto en protección social aumentó de forma especialmente rápida, de un $12.1 \%$ del PIB en 1975 a un 17.2\% sólo cinco años más tarde (VELARDE, 1990: 109).

Tres factores diferentes ayudan a explicar este tremendo incremento en el gasto social financiado por la deuda pública. El primero era el producto de acontecimientos económicos intemacionales. Las dos recesiones que siguieron a las acrisis del petróleor de 1973 y 1979 crearon un entorno que era sustancialmente diferente de aquél estable y próspero de comienzos de los 70 . Como resultado de las altas tasas de crecimiento económico de aquellos primeros años, y de la sustancial migración de la fuerza de trabajo excedente a los países europeos vecinos en los 60 y a principios de los 70, las tasas de desempleo en España anteriores a 1975 eran muy bajas. En 1973, por ejemplo, sólo un $2.7 \%$ de la fuerza de trabajo española estaba desempleada (FlaQUER et al., 1990: 28). En contraste, el período de 1975 hasta mediados de los 80 fue un período marcado por las repetidas crisis económicas. Debido a serias recesiones nacionales y la repatriación de trabajadores emigrantes de nuevo sobrantes del exterior, el desempleo en España se elevó a un $9.5 \%$ de la fuerza de trabajo en 1979 , y a un $17 \%$ en 1983 (ibid.). Por tanto, una gran parte de la expansión del gasto social y de los déficit presupuestarios resultaron de un incremento en los pagos por desempleo y de la reducción de la base impositiva como consecuencia de la crisis.

Interactuando con esta variable económica había un factor más explícitamente político: los requisitos especiales de la transición a la democracia. El éxito de aquella transición dependia en parte del apoyo de todos los sectores políticamente significativos de la sociedad española, algo que habría sido más difícil de lograr si las relaciones sociales hubieran estado polarizadas como resultado del duro desposeimiento económico de un considerable sector de la población. En consecuencia, los a ajustes estructurales económicos que podrían haber agravado la situación de desempleo fueron pospuestos (ver Maravall, 1995: 108112), y los aumentos masivos en gasto social (especialmente los pagos por el seguro de desempleo) fueron puestos en práctica para suavizar los efectos de la crisis económica. De hecho, antes que cerrar definitivamente empresas ineficientes en el sector paraestatal o dar otros pasos dolorosos hacia el incremento de su competitividad (como harían los gobiemos del PSOE de los 80), los gobiemos de Suárez incrementaron los flujos de subsidios a las empresas débiles y nacionalizaron aquellas que de otra forma podrían haberse hundido por completo ${ }^{12}$. Al mismo tiempo que se estaban llevando a la práctica esos incrementos en el gasto, los aumentos de los impuestos se mantuvieron moderados, en parte para proporcionar un estímulo económico contracíclico, en parte para evitar alienar a los estratos sociales medios y altos del proceso de democratización, y en parte para conservar el apoyo electoral de aquellos grupos sociales. En suma, los incrementos masivos en el gasto social y la presupuestación del déficit eran los componentes integrales de la estrategia altamente exitosa del gobierno de Suárez para mejorar las tensiones sociales durante la transición y la consolidación del nuevo régimen democrático. Al mismo tiempo, debe apuntarse que las políticas macroeconómicas que se adoptaron como el producto final de esta estrategia política eran compatibles con las políticas contracíclicas keynesianas adoptadas por la mayoría de los gobiernos europeos occidentales durante las primeras tres décadas siguientes a la Segunda Guerra Mundial.

Finalmente, estas políticas eran producto de los cambios fundamentales en los procesos de toma de decisiones políticas (que serán descritos extensamente en este artículo más adelante), que eran elementos centrales en la creación misma del nuevo régimen democrático. En contraste con los procesos de deliberación cerrados bajo el franquismo, las decisiones más importantes tomadas durante este primer período (julio 1977-diciembre 1978) se caracterizaron por la extraordinariamente amplia participación de los representantes tanto del Gobiemo como de los grupos políticos de la oposición. Esto era especialmente pronunciado en las negociaciones sobre los llamados Pactos de la Moncloa, además de la redacción de una Constitución democrática. Este acuerdo comprometió al Gobierno a continuar con las reformas de las instituciones políticas y el sistema de imposición regresivo heredado del régimen franquista; a aumentar las transferencias del Presupuesto estatal al sistema de la Seguridad Social y una expansión de los programas de protección social; a controles gubernamentales sobre el incremento de los precios, a mejoras sustanciales en el sistema de educación pública; y a otros cambios en las políticas públicas. A cambio de esto, los partidos socialista y comunista se comprometieron a persuadir a los dos sindicatos sobre los cuales tenían influencia para que se abstuvieran de llevar a cabo una actividad huelguista excesiva, limitar sus demandas de incrementos salariales a un 22\% (el nivel estimado de inflación para ese año), y a aceptar políticas monetarias y de gasto más restrictivas.

Si nos podemos referir a este período (1977-1978) como el de la política del consenso, las circunstancias de la toma de decisiones políticas que siguieron puede denominarse como :la política del disenso. Comenzando con la investidura de un nuevo Gobiemo de la UCD bajo Adolfo Suárez tras la ratificación de la nueva Constitución, se caracterizó por conflictos partidistas e intrapartidistas considerables y a menudo vengativos, además del abandono de las normas consensuales sobre la toma de decisiones. En algunos aspectos, esta segunda fase simplemente reflejó el paso de la transición de un régimen a la •política usual. (De hecho, las clases de consultas interpartidis- 
tas amplias y las prácticas de tomá de decisiones consensuadas que habían caracterizado el período anterior son atípicas de las democracias consolidadas, y se encuentran normalmente sólo en edemocracias consociacionales" [consociational democracies] y en algunos paises escandinavos). En consecuencia, el Gobierno minoritario de UCD (que fue capáz de mantenerse en el poder en parte como resultado de las disposiciones de la Constitución relativas a la moción de censura constructiva de no confianza) limitó en gran medida las negociaciones interpartidistas a asegurarse los votos parlamentarios adicionales necesarios para aprobar la legislación en las Cortes, en una forma que es típica de la mayoría de los otros sistemas democráticos.

La intensidad del conflicto inter e intrapartidista durante este período, sin embargo, fue extraordinaria. Una línea de conflicto opuso al principal partido de la oposición, el PSOE, y al Gobiemo de la UCD. Frustrado por las consecuencias del fracaso electoral en 1979, el partido socialista redobló sus ataques a Adolfo Suárez en lo que resultó ser un esfuerzo altamente exitoso para socavar tanto el apoyo electoral como la cohesión interna de la UCD. Pronto siguieron la crítica intensa a Suárez desde dentro de su propio partido y el brote de pendencias entre facciones, que culminaron en la dimisión de Suárez como líder del partido y como Presidente del Gobiemo en enero de 1981. Un intento de golpe militar durante el debate parlamentario de investidura del nuevo Presidente del Gobierno, Leopoldo Calvo Sotelo, el 23 de febrero de 1981, interpuso un nuevo elemento de inestabilidad en una atmósfera política ya de por sí turbulenta. Aunque los primeros meses bajo el gobierno de Sotelo supusieron un respiro de su Sturm und Drang, el disenso intrapartidista una vez más alcanzó proporciones de crisis a finales de 1981, que culminaron un año más tarde en la disolución de la UCD tras una devastadora derrota electoral. Aparte del cada vez más complicado entorno en la trama de decisiones durante este período, hubo un nuevo deterioro de la economía española a comienzos de los 80 tras la esegunda crisis del petróleo. El crecimiento económico se interrumpió bruscamente, la inflación en el coste de vida se situó entre un 14.4 y un 15.7 durante este periodo, y en torno a 1982 el nivel de desempleo había alcanzado un $16.2 \%$ de la fuerza de trabajo (ALCAIDE, 1994: 66; y MaraVALL, 1995: 119). En general, podría decirse que la toma de decisiones desde 1979 hasta 1982 tuvo lugar dentro de un entomo extremadamente difícil y turbulento.

Sin embargo, en términos de política fiscal y de gasto, el período de 1979 a 1982 se caracterizó por la continuidad respecto de la fase anterior y las tendencias de políticas públicas puestas en marcha por la transición y los Pactos de la Moncloa. El volumen de ingresos fiscales (como porcentaje del PIB) continuó incrementándose a un ritmo de alrededor de un $1 \%$ al año, y el gasto total del gobierno continuó aumentando alrededor de un $2 \%$ del PIB al año. La ampliación significativa de la cobertura de la población española por el sistema de Seguridad Social, además de los incrementos del gasto en educación, también reflejaron la continuidad con la primera fase. En términos de distribución funcional de los recursos del Gobierno, el rasgo más destacable era que el gasto en protección social completó su período de crecimiento más rápido durante este período. Entre 1975 y 1983, el gasto en los programas de protección social se elevó de un $12.1 \%$ del Producto Interior Bruto a un $19.5 \%$. Tras este aumento repentino en el crecimiento, el gasto en estos servicios se niveló un poco: mientras que el gasto en protección social continuó creciendo en términos reales durante los 80 , como parte del PIB sólo aumentó de un 19.5 a un 20.1 entre 1983 y 1989 (VELARDE, 1990: 109; y RODRíGUEZ CABRERO, 1994: 1449). En general, puede decirse que los legados presupuestarios más importantes de los Gobiernos de la UCD que abarcaron los dos primeros períodos de las políticas públicas fueron pasos iniciales para corregir las deficiencias en los sistemas de educación e imposición, además de incrementar la provisión de los servicios de protección social.

La elección de un Gobierno de mayoría socialista en noviembre de 1982 inició la tercera fase. Durante este período (que finalizó en 1989), los Gobiemos del PSOE bajo Felipe González disfrutaron de sustanciales mayorías parlamentarias. Además, la democracia española se consolidó definitivamente cuando el primer Gobierno del PSOE llegó al poder. El rasgo definitorio de esta tercera fase fue, por tanto, la ausencia de restricciones a las opciones de las políticas públicas del Gobierno, resultantes de las enormes preocupaciones por las exigencias políticas de la transición (el aspecto dominante de la primera fase) o la inseguridad extrema característica de un partido en el Gobierno asentado sobre facciones carente de una mayoría parlamentaria en una época de recesión económica mundial (que caracterizó a la segunda fase). En consecuencia, los Gobiemos de González de 1982-89 prestaron toda su atención a la tarea de resolver los problemas estructurales de la economía española y, más ampliamente, de completar la •modernización. de la sociedad española.

La estrategia seguida por los Gobiernos de González fue diferente de la de los Gobiernos anteriores de la UCD en un aspecto fundamental. El principal empuje macroeconómico de las políticas presupuestarias de la UCD había sido emplear métodos keynesianos tradicionales para estimular la demanda con el fin de combatir los efectos de la recesión a corto plazo, mientras que al mismo tiempo confiaba en los acuerdos neocorporativistas entre los trabajadores, empresarios y el Gobierno, para reducir la tasa de inflación. En contraste con estas políticas del lado de la demanda, los Gobiemos del PSOE optaron por una nueva mezcla de políticas del lado de la demanda y de la oferta, cuyo objetivo principal era un aumento de la competitividad de la economía española a largo plazo (ver Maravald, 1993: 9496). 
El abandono del keynesianismo tradicional del lado de la demanda era parte de una tendencia más amplia patente en un número de países industrializados, y fue provocada por el fracaso altamente visible del nuevo Gobiemo socialista de Francia para estimular su salida de la recesión mundial (ver Borx, 1994: cap. 2, 1; y Maravall, 1995: 120).

Una razón adicional para cambiar hacia una perspectiva del lado de la oferta a largo plazo fue que España necesitaba prepararse para entrar en la Comunidad Europea. Varios legados del período franquista especialmente el amplio e ineficiente imperio paraestatal del INI ( $80 \%$ de cuyas empresas perdian dinero (Maravall, 1995: 124]), una fuerza de trabajo extremadamente inflexible, una mentalidad no-competitiva entre los empresarios del sector privado que se habían aislado de las fuerzas de la competición durante las décadas del corporativismo estatal, la regulación poco flexible (en los 40 y 50 ), la autarquía y el aislamiento internacional hicieron de las empresas industriales espanolas unas empresas poco adecuadas para competir con éxito con las de otros países miembros de la Comunidad Económica. En resumen, antes de la entrada en la CE (que tuvo lugar el 1 de enero de 1986), sería necesario modernizar la economía española y obligarla a ser más eficiente.

Una faceta de la estrategia económica del PSOE era un programa de ereconversión industrial. orientado hacia la mejord de la competitividad del sector paraestatal. Se despidió a decenas de miles de trabajadores que sobraban (ver SHARE, 1986; y The Financial Times, de 18 de enero de 1985: 6), se cerraron plantas ineficientes, y algunas empresas (incluida la fábrica de automóviles, SEAT) se vendieron al sector privado. Pero esto no puede considerarse como un programa de "privatización" del estilo iniciado por Margaret Thatcher. Nunca se intentó transferir la mayor parte de las industrias nacionalizadas a manos privadas, sino más bien mejorar la eficiencia de aquellas empresas, centrándose en las actividades de las industrias paraestatales en sectores clave dentro de las cuales podrían disfrutar de una ventaja competitiva (ver Box, 1994: cap. 2, 28). Como resultado, el ámbito de la privatización fue claramente limitado. No obstante, el cierre de los astilleros y altos hornos (particularmente en Valencia y Galicia) provocó protestas amargas y a veces violentas por parte de los trabajadores despedidos, e introdujo una cuna entre el Gobiemo del PSOE y su sindicato socialista aliado, la UGT. Otras facetas de la política económica del Gobiemo incluian una política monetaria relativamente restrictiva, algunas reformas del mercado y la remoción de ciertas regulaciones del Gobiemo que habian socavado la competitividad (FLAQUER, GINER Y MORENO, 1990: 48). Estas políticas dieron lugar a acusaciones acerca de que el PSOE había abrazado una estrategia económica •neoliberal.

En términos de política presupuestaria, sin embargo, los Gobiernos de González adoptaron una estrategia del lado de la oferta que incluyó varias innovaciones que diferenciaron a la variante socialdemócrata. espanola de las versiones conservadoras presentes en todas partes. En contraste con los situados en el lado de la oferta en los Estados Unidos (que poseen una creencia casi religiosa en la superioridad inherente del mercado sobre todas las formas de actividad gubernamental, y en la capacidad de la llamada -Curva de Laffer para equilibrar el presupuesto recortando los impuestos [sic)], la estrategia del lado de la oferta de los socialistas españoles se basó en la idea de que los gobiemos deben desempeñar roles importantes en el establecimiento de las condiciones favorables para el crecimiento económico a largo plazo, y en la corrección de las imperfecciones del mecanismo del mercado. Por tanto, el PSOE trató de atraer la inversión y maximizar el crecimiento a largo plazo, manteniendo fundamentalmente una política macroeconómica estable y sostenida, pero, al mismo tiempo, trató de intervenir en la economía para mitigar los problemas del desempleo y el subdesarrollo regional. En oposición a la estrategia americana del lado de la oferta, esto requirió aumentos en los flujos de ingresos fiscales que permitiesen desembolsar un gasto público mayor en capital fijo y humano (Borx, 1994: part. 2, 1; ver también Maravall, 1993: 94-96, y 1995: 121-124).

En algunos aspectos, estas políticas no supusieron una desviación significativa con respecto de las de los anteriores Gobiernos de la UCD. El PSOE se basó en las reformas fiscales que se habían iniciado en 1977, añadiéndoles una serie de reformas incrementales adicionales durante varios años. El primer paso (que comenzó en 1983) fue adoptar unas medidas enérgicas nuevas contra la evasión fiscal. El incremento significativo en los ingresos del impuesto sobre la renta que tuvo lugar posteriormente, junto con los efectos interactivos del paso gradual a tasas impositivas más elevadas (bracket creep) y la inflación, condujo a un aumento constante del flujo de los ingresos fiscales para el Estado. A esto siguieron incrementos en la tasa de imposición marginal máxima sobre los españoles más opulentos y cortes impositivos para los más pobres, haciendo mucho más progresivo el impuesto sobre la renta como medio de compensar la regresividad de otros impuestos (ZaLDívar y CASTELLS, 1992: 128; y BoIX, 1994: capítulo 3, 22-26). Algunos de los efectos de estos cambios incrementales en el sistema tributario pueden verse en las Tablas 2 y 3

Como revelan los datos de la Tabla 2 , el nivel global de imposición en España se había incrementado en la década anterior a la transición a la democracia, pero todo ese incremento se explicaba por los aumentos en las contribuciones regresivas a la Seguridad Social que no estaban bajo el control del Ministerio de Hacienda. Cuando se eliminan de ese total los impuestos a la Seguridad Social, es claro que no ha habido un cambio significativo en el nivel global de ingresos disponibles para el Estado español durante los 12 años anteriores a la transición. Los efectos de las reformas fiscales moderadas de la UCD pueden verse 
Tabla 2

Ingresos por impuestos como porcentaje del Producto Interior Bruto, 1965-1993

\begin{tabular}{|c|c|c|c|c|}
\hline \multirow{2}{*}{ Año } & \multicolumn{2}{|c|}{ Todos los Ingresos fiscales como $\%$ del PIB } & \multicolumn{2}{|c|}{$\begin{array}{l}\text { Todos los Ingresos fiscales excepto la Seguridad Social } \\
\text { como } \% \text { del PIB }\end{array}$} \\
\hline & España & Media de la OCDE & España & Media de la OCDE \\
\hline \multicolumn{5}{|l|}{ (Régimen franquista): } \\
\hline 1965 & 14.7 & 26.5 & 10.5 & 21.5 \\
\hline 1970 & 16.9 & 29.7 & 10.6 & 23.9 \\
\hline 1975 & 19.5 & 32.7 & 10.3 & 25.1 \\
\hline \multicolumn{5}{|l|}{ (Gobierno de la UCD): } \\
\hline 1977 & 21.4 & 34.6 & 11.0 & \\
\hline 1980 & 24.1 & 35.0 & 12.4 & 26.6 \\
\hline 1982 & 25.6 & 36.3 & 13.6 & \\
\hline \multicolumn{5}{|l|}{ (Gobiemo del PSOE): } \\
\hline 1985 & 28.8 & 36.9 & 16.9 & 27.9 \\
\hline 1987 & 32.5 & 37.9 & & \\
\hline 1990 & 34.4 & 38.0 & 22.2 & 28.7 \\
\hline 1993 & 35.1 & 38.7 & 21.7 & 28.5 \\
\hline
\end{tabular}

Fuente: OCDE, Estadisticas de ingresas de los Paises Miembros de la OCDE, 1965-1994, 73-74 (para todos los años excepto 1977 y 1982, de los volúmenes de las Estadisticas de Ingresas de 1979 y 1984)

en un incremento en los ingresos no de la Seguridad Social de un $11 \%$ a un $13.6 \%$ del PIB en los cinco años siguientes. Modificaciones adicionales en el sistema de imposición bajo los exitosos gobiernos socialistas, sin embargo, incrementaron el flujo de ingresos a un ritmo mucho más rápido. En conjunto, entre 1977 y 1990, el volumen de los impuestos no-Seguridad Social sobrepasaron el doble. Mientras que esto generó muchos ingresos para la financiación de los programas del gasto público, los niveles de imposición de España todavía continuaron por debajo de la media de la OCDE.

Posteriormente, la Tabla 3 revela que una gran parte de ese incremento se generó como consecuencia de una mayor confianza en un impuesto sobre la renta cada vez más progresivo y personal. Al mismo tiempo, el crecimiento de la imposición en la Seguridad Social (que, aparte de su regresividad, tuvo un impacto negativo en la creación de empleo) se detuvo tras la democratización del sistema político de España: se niveló como porcentaje del PIB, y de hecho descendió como porcentaje de los ingresos fiscales totales. Este desarrollo fue posible en parte como resultado de un incremento sustancial en el nivel de transferencias al sistema de la Seguridad Social de fondos de los ingresos generales del Presupuesto del Estado. Como se ha mencionado anteriormente, el nivel de estas transferencias bajo el régimen de Franco había sido extraordinariamente bajo. En 1977, cuando el primer Gobierno elegido democráticamente llegó al poder, sólo un 3.0\% de los ingresos del sistema de la Seguridad Social procedía de las transferencias del Presupuesto del Estado.

En el último año de gcbierno de la UCD (1982), este porcentaje se había elevado a un 14.9\%. En 1994, sin embargo, el $34.8 \%$ de los ingresos del sistema de la Seguridad Social procedian de las transferencias del Presupuesto del Estado ${ }^{13}$. En términos generales, puede decirse que las políticas impositivas del PSOE reflejaron la continuidad con las reformas fiscales iniciadas en 1977, pero aceleraron las tendencias hacia la progresividad y los mayores ingresos revelan que fueron establecidos por el primer Gobierno de la UCD.

La nota distintiva de las políticas presupuestarias del PSOE se hace más patente respecto del gasto. El legado más notable de las prioridades de gasto de la UCD había sido la extensión de los 
Tabla 3

La estructura de la imposición, 1965-1993

\begin{tabular}{|c|c|c|c|c|}
\hline Año & $\begin{array}{l}\text { Impuestos sobre th Renta personal } \\
\text { Porcentaje de la Imposición total }\end{array}$ & Porcentaje del PIB & $\begin{array}{l}\text { Impuestos de la Seguridad Social } \\
\text { Porcentaje de la Imposición total }\end{array}$ & Porcentaje del PIB \\
\hline \multicolumn{5}{|c|}{ (Régimen franquista): } \\
\hline 1965 & $14.3 \%$ & $2.1 \%$ & $28.3 \%$ & $4.2 \%$ \\
\hline 1970 & 11.5 & 1.9 & 37.4 & 6.3 \\
\hline 1975 & 14.5 & 2.8 & 47.5 & 9.3 \\
\hline \multicolumn{5}{|c|}{ (Gobierno de la UCD): } \\
\hline 1978 & 17.0 & 3.9 & 49.5 & 11.3 \\
\hline 1980 & 20.4 & 4.9 & 48.6 & 11.7 \\
\hline 1982 & 19.8 & 5.0 & 46.5 & 11.8 \\
\hline \multicolumn{5}{|c|}{ (Gobiemo del PSOE): } \\
\hline 1985 & 19.7 & 5.7 & 41.3 & 11.9 \\
\hline 1987 & 21.4 & 7.0 & 36.2 & 11.8 \\
\hline 1991 & 23.3 & 8.1 & 35.6 & 12.4 \\
\hline 1993 & 24.0 & 8.4 & 38.1 & 13.4 \\
\hline
\end{tabular}

Fuente: (Para todos los aǹos excepto 1978, 1982 y 1987) OCDE, Estadisticas de ingresox, 1965-1994, 77 y 79; (para 1978, 1982 y 1987), OCDE, ediciones de Estadisticas de ingresos de 1980, 1984 y 1993.

programas de protección social. De acuerdo con la estrategia de desarrollo del lado de la oferta socialdemócrata de los Gobiernos socialistas, el impacto decisivo de la políica presupuestaria del PSOE puede verse en el incremento del gasto en educación y las inversiones de capital estatal. Los socialistas continuaron expandiendo incrementalmente los programas de protección social, y acometieron algunas iniciativas nuevas en este sector ${ }^{14}$, pero dieron mayor prioridad al desarrollo de la infraestructura social y física. Estas tendencias pueden observarse en la Tabla 4.

Los desgraciadamente bajos niveles de gasto en educación bajo el régimen de Franco se elevaron significativamente. Los Gobiernos de la UCD de 1977-82, de acuerdo con los compromisos incorporados en los Pactos de la Moncloa, habían incrementado sustancialmente los gastos en educación, pero fue sólo en los 80 cuando el gasto español en educación se aproximó a los niveles típicos de otras democracias occidentales. Esto fue acompañado de incrementos espectaculares en las tasas de matriculación en la educación superior y secundaria.

Entre 1982 y 1994, el porcentaje de jóvenes entre 14-15 años escolarizados aumentó de 76.9 a $99.7 \%$, mientras que las tasas de matrícula entre aquéllos con edades comprendidas entre los 16-17 años aumentaron del 57.3 a un 78\% (Anuario El Pais, 1995: 117). Durante este mismo período de tiempo, el número de estudiantes universitarios superó el doble, de 640.000 en 1979 a casi 1.4 millones, haciendo de la tasa de matriculación universitaria de España (alrededor de un 37\% de aquéllos con edades comprendidas entre 20-24 años en 1993) una de las más altas de Europa ${ }^{15}$. En el nivel agregado, a finales de los 80 podría decirse que el sistema de educación español había pasado, en menos de una década, de ser el más pobremente desarrollado en el mundo industrializado a uno que, en términos de indicadores cuantitativos, supera a la mayoría de los países europeos occidentales.

Junto con las duras obligaciones presupuestarias destinadas a fortalecer la infraestructura social para el desarrollo económiCo, el PSOE también realizó sustanciales inversiones en la infraestructura física del país. Como revela la Tabla 4, el nivel de las inversiones de capital estatal casi doblaba el porcentaje del PIB entre 1980 y 1985, y casi la triplicaba en 1992. Entre otras cosas, esto hizo posible una mejora masiva del sistema de transporte del país. El que había sido el peor sistema de autopistas (junto con el de Portugal) de la Europa occidental en los 70, se 
Tabla 4

La Evolución de los Gastos Públicos Españoles, 1963-1994

\begin{tabular}{|ccccc|}
\hline & \multicolumn{5}{c|}{ Porcentaje del Producto Interior Bruto Gastado en ... } \\
Año & Educación & Defensa & Protección Social & Inversiones en Capital estatal \\
\hline $1963 / 64$ & $1.5(1964)$ & 2.1 & - & 2.1 \\
1970.73 & $2.1(1973)$ & $1.5(1973)$ & $9.5(1970)$ & $2.7(1970)$ \\
1975 & 2.2 & 1.7 & 12.1 & 2.7 \\
1980 & 3.3 & 2.0 & 18.1 & 1.9 \\
$1985 / 86$ & $3.6(1985)$ & $2.0(1985)$ & $19.5(1980)$ & $3.7(1985)$ \\
$1989 / 90$ & $4.1(1990)$ & $1.7(1990)$ & $20.1(1989)$ & $4.9(1990)$ \\
$1991 / 92$ & 4.3 & 1.6 & 22.5 & $5.2(1992)$ \\
1994 & 4.7 & - & - & - \\
\hline
\end{tabular}

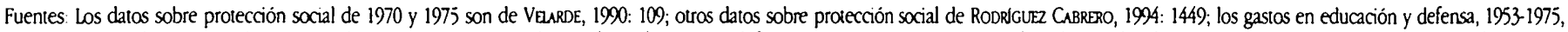

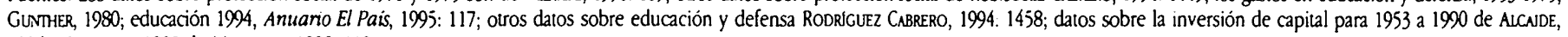
1994: 72, y para 1992 de Maravall, 1995: 112

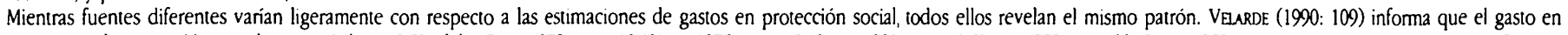

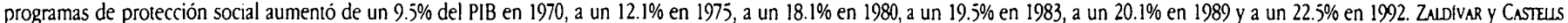

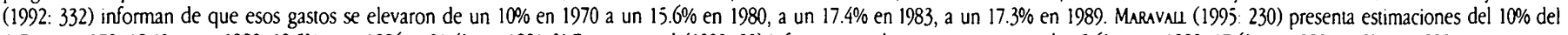
PIB para 1970, 18.1\% para 1980, 19.5\% para 1986, y 21.4\% en 1991. Y FuQuer et al (1990: 50) informan que las estimaciones son de $15.6 \%$ para $1980,17.6 \%$ en 1983, y $18 \%$ en 1990.

transformó a finales de los 80 en uno de los mejores, con autopistas con varios carriles que unían virtualmente todas las regiones de España (excepto Galicia). Estas inversiones estatales fueron acompañadas de un incremento sustancial en las inversiones de capital extranjero y del sector privado en España entre 1985 y 1990 . Tras un período de inversión negativa durante la década precedente caracterizada por la recesión (1975-85), el nivel global de la inversión de capital se incrementó de un $19.5 \%$ a un $24.4 \%$ del PIB (ZaLdívar y CASTELIS: 81 ). Debe apuntarse que esto representó un alejamiento de las políticas de la UCD más en la práctica que en la intención: los economistas de la UCD, como sus homólogos en el PSOE, también desearon incrementar el gasto en inversión, pero se contuvieron, en gran medida, por las profundas recesiones del período anterior, y la urgente necesidad de adoptar políicas contracíclicas estimulantes e incrementar rápidamente el gasto en programas de protección social.

El nivel global de gasto del Gobierno continuó incrementándose durante los 80 y principios de los 90 , como puede verse en la Tabla 5 . Aunque el período de crecimiento más rápido del gasto público tuvo lugar a finales de los 70 (acompañando la transición a la democracia), doce años de gobiemo del PSOE elevaron el nivel agregado de los gastos del Gobierno a un 44.3\% del PIB en 1994. Este incremento del gasto no se com- pensó con el aumento de flujos de ingresos, resultando de todo ello déficit presupuestarios considerables durante el período, que hincharon sustancialmente la deuda acumulada del sector público. La pequeña cuantía de la deuda pública acumulada heredada del período franquista, significó, no obstante, que incluso a mediados de los 90 la deuda pública española estaba próxima a la deuda acumulada media de las democracias occidentales.

Aunque no he tenido intención de intentar atribuir a estas políticas desarrollos macroeconómicos posteriores, merece la pena destacar que durante el periodo de 1985-1990, España experimentó una tasa de crecimiento económico significativamente más rápida (4.5\%) que la media de los países miembros de la Comunidad Europea (3.1\%), y su tasa de crecimiento de 5.6\% para 1987 era la más alta de la Europa occidental (ALCAIDE, 1994: 58; ZALDínar y Castells, 1992: 81; y Flaquer el al., 1990: 48). Esta tasa de desarrollo económico demuestra claramente que (en oposición a la fuerte relación inversa y determinista formulada por los americanos del lado de la oferta y los conservadores en economía) el crecimiento económico no es incompatible con el incremento de los niveles de imposición fiscal y de gasto del Gobierno.

El cuarto período relativo a las circunstancias de la toma de decisiones empezó en 1989, con la pérdida del PSOE de la mayoría absoluta en el Congreso de los Diputados. Mientras que el 
Tabla 5

Gastos Públicos, Déficits Anuales y Endeudamiento Público (en porcentaje del PIB)

\begin{tabular}{|c|c|c|c|c|}
\hline Año & $\begin{array}{l}\text { Total de Gastos Públicos } \\
\text { (en \% de PIB) }\end{array}$ & $\begin{array}{c}\text { Gastos Medios de la CE } \\
\text { (en \% de PIB) }\end{array}$ & $\begin{array}{c}\text { Déficit Presupuestario } \\
\text { (en \% de PIB) }\end{array}$ & $\begin{array}{c}\text { Devda Publica acumulada } \\
\text { (en \% de PIB) }\end{array}$ \\
\hline 1965 & 19.7 & - & 0 & \\
\hline 1:xio & 22.2 & 39.2 & 0 & . \\
\hline $1974 / 5$ & $24.9(1975)$ & $44 . j(1975)$ & 0 & $1920(1974)$ \\
\hline 1980 & 33.7 & 46.0 & 1.3 & \\
\hline 1982 & 38.2 & & & \\
\hline 1985 & 42.7 & 49.0 & 3.1 & \\
\hline 1990 & 43.3 & 46.0 & 2.5 & 36.6 \\
\hline $1992 / 3$ & & & 7.3 & $46.1(1963)$ \\
\hline 1994 & 44.3 & & & ${ }^{*}$ \\
\hline
\end{tabular}

Fuentes: Para los datos sobre el gasto español, 196j-90, ALCAIDE, 1994: 72; media de la CE 1970-90, ALCNDE, 1988; total espanol de gastos para 1994, Ministerio de Economia y Hacienda, El presupuesto para 1995, Ley 41/194, de 30 de diciembre, de Presupuestos Generales del Estado para 1995, Madrid, 1995, 60; PIB de 1994 de la Dirección General de Previsión y Coyuntura, Ministerio de Economia y Hacienda, Síntesis de indicadores económicos., MAY, 1995: 25; déficits presupuestarios de 1980-9 de RodriGuez CaBRERO, 1994: 1447, y para 1993 MARAVAL, 1995: 125; cifras del déficit presupuestario para 1965.75 (sólo para la Administración del Estado) Guntrier, 1980: 79; deuda pública acumulada 1974 del Secretario General Técnico, Ministerio de Hacienda, comunicación personal; deuda acumulada 1990 y 1993, Ministerio de Economia y Hacienda, El presupuesto para 1995, 44.

boicot continuo de las Cortes por parte de los diputados del partido separatista y antisistema vasco Herri Batasuna significaba que el PSOE continuaría detentando una mayoría relativa del voto en el Congreso, su capacidad para aprobar la legislación llegó a ser de alguna forma más precaria de lo que había sido en las dos legislaturas anteriores, en las cuales el partido había disfrutado de mayorías sustanciales. Esto, junto con la sustitución de Alfonso Guerra por Narcís Serra como Vicepresidente del Gobierno, marcó el principio de una fase diferente del Gobierno del PSOE. La pérdida completa de la mayoría parlamentaria en las elecciones de 1993 hizo aún más pronunciadas las características de este período.

Al principio de este período, la relación en otro tiempo más cercana entre el PSOE y su sindicato aliado, la UGT, se había roto completamente. Por tanto, no fueron posibles los acuerdos neocorporativistas que se orientaban hacia la contención de las demandas salariales excesivas para combatir la inflación (ver Maravall, 1993: 119). El PSOE consiguió pactar solamente una vez con la UGT y la CEOE en 1985, y a principios de los 90 trató de contener las presiones inflacionistas, adoptando políticas monetarias severamente restrictivas (MARAvall, 1995: 124-5). Reaccionando contra estas medidas de austeridad, las protestas de los sindicatos fueron en aumento, culminando en dos huelgas generales. La recuperación económica a finales de los 80 también tuvo un duro final, y el desempleo se elevó a un $24 \%$ de la población activa en 1994. En resumen, un empeoramiento de las relaciones laborales y la renovada crisis económica habían llegado a ser rasgos claves del entorno de la política de este período. A pesar de este cambio en las circunstancias, sin embargo, las políticas presupuestarias del Gobierno permanecieron en gran medida inalteradas. Una recuperación económica fuerte que empezó en la primera mitad de 1995 pareció reivindicar la continuidad de estas políticas públicas.

\section{Procesos de toma de decisiones}

Los procesos de toma de decisiones presupuestarias han variado significativamente desde la elección del primer Gobierno democrático de España después de Franco en 1977. Estas variaciones implican que es inapropiado describir la toma de decisiones en España como caracterizada por un único eestilo de políticas públicasn (cf. SuBirats, 1992). Pero la conclusión más importante que se puede extraer de un examen de la toma de decisiones durante este período es que todos estos procesos - a pesar de las variaciones de uno a otro en los cuatro periodos anteriormente mencionados - eran profundamente diferentes de 
los procesos de toma de decisiones bajo el régimen del General Franco. Los cambios dramáticos en las políticas de imposición y gasto arriba esbozadas son el producto de esta alteración fundamental de las prácticas gubernamentales de toma de decisiones.

En contraste con el régimen franquista, en donde ninguna figura políica ccentral. establecía las grandes líneas de las prioridades del Gobierno, en todos los Gobiernos de Adolfo Suárez, Leopoldo Calvo Sotelo y Felipe González, el Primer Ministro y/o sus colaboradores cercanos ejercieron un control directo sobre el establecimiento de las prioridades del gasto. Los Ministros de Hacienda continuaron dirigiendo las negociaciones bilaterales privadas con los ministros individuales que efectuaban el gasto, en las fases finales y decisivas del proceso presupuestario, pero de ninguna manera eran tan autónomos en el desempeño de este papel como lo habían sido bajo el régimen de Franco. En consecuencia, las prioridades presupuestarias "de orden superior" eran establecidas explícitamente por estas figuras políticas centrales, y no surgían como el producto de facto de tratos cerrados entre los Ministros de Hacienda y los que realizaban el gasto. También en contraste con la era franquista, cuando los Ministros, en tanto que individuos, sólo eran responsables ante el Jefe del Estado, la toma de decisiones en la era democrática se basa y está constreñida por una conciencia mucho más precisa de la responsabilidad colectiva del Gobierno ante la sociedad y el electorado. Esto ha conducido a una agregación de intereses mucho más efectiva - una función que fue muy pobremente desarrollada bajo el sistema autoritario anterior. Y como ha argumentado Arvid LUKAuSKas (1992), esto ha hecho que los Ministros del Gobierno sean más conscientes de la necesidad de apelar al votante medio (que, en España, está situado justo en el centro-izquierda), y por tanto, a formular políticas que son mucho más progresistas y orientadas a la maximización de la producción de bienes colectivos, en comparación con el énfasis mucho mayor hecho sobre las élites económicas atrincheradas y recompensadas que caracterizaron la era franquista. En términos de participación directa en el proceso de elaboración de las políticas públicas, también los grupos de fuera de la Administración del Estado (que bajo el franquismo no tuvieron un papel institucionalizado en el establecimiento por parte del Gobierno de las prioridades de gasto) han ejercido firmemente alguna influencia, y a veces han tenido una influencia directa y decisiva en el establecimiento de las políticas públicas. Finalmente, la pasividad general de las Cortes bajo Franco ha dado lugar a varios modelos de implicación parlamentaria que van de una a otra de las cuatro fases antes mencionadas, pero en todas las fases las Cortes son más activas e influyentes de lo que lo fueron bajo el régimen autoritario.

Sólo una de las características distintivas de la toma de decisiones franquista ha continuado en la era democrática: los Ministros del Gobierno todavía son relativamente autónomos para establecer políticas que caen dentro de las jurisdicciones de sus respectivos departamentos. Durante el período que está siendo investigado aquí (1977-1996), sólo cuando surgían temas altamente controvertidos (tales como la legalización del divorcio, las políticas monetarias restrictivas de los Ministros de Hacienda del PSOE, el programa de Reconversión Industrial, y tres de las cuatro Leyes Orgánicas relativas al sistema de educación), un conjunto más amplio de fuerzas sociales (partidos, organizaciones secundarias $y$, a veces, movilizaciones de masas) ejercía una influencia significativa sobre el Ministro del Gobiemo pertinente. Y el Consejo de Ministros solamente se encargaría de las discusiones entre Ministros que afectasen a más de una jurisdicción departamental, o de asuntos planteados en el Consejo por un Ministro que consideraba que una de sus propuestas de políticas públicas era de tal trascendencia política como para requerir una deliberación ministerial más amplia. Reflejando esta continuidad general de la autonomía jurisdiccional de los ministros, una gran cantidad de lobbies particulares continúa centrándose en los Ministros individuales. Es probable que este elevado nivel de autonomía ministerial sea un producto del grado en que se ha concentrado la autoridad sobre la toma de decisiones en el Consejo de Ministros, junto con la debilidad general del Parlamento como cuerpo de toma de decisiones independiente, como en Gran Bretaña (en contraste con la amplia dispersión de poderes, como ocurre en los Estados Unidos).

\section{Cuatro fases de la toma de decisiones}

La primera fase de la toma de decisiones democrática, de junio de 1977 hasta marzo de 1979, estuvo dominada por la primacía de la políica sobre la economía. El objetivo principal del Gobierno de Suárez era completar la transición a la democracia y consolidar ese nuevo sistema asegurándose el apoyo positivo de todos los sectores de la sociedad española políticamente significativos. .La política del consenson se caracterizó, de este modo, por dos rasgos que no serían típicos de la epolítica de costumbre, o de ninguno de los tres períodos posteriores. El primero fue un marcado esfuerzo por evitar compromisos sustantivos que serían considerados como inaceptables por cualquier grupo políticamente significativo o que polarizaran innecesariamente a la sociedad, minando, por tanto, las expectativas de la aceptación consensuada del nuevo régimen. En términos sustantivos, esto condujo a la posposición de cualquier consideración sobre políticas de ajuste estructural, a políticas fiscales relajadas y a una gran expansión de los programas de protección social (en parte, como respuesta a las penurias cada vez mayores causadas por la crisis económica). Como ha argu- 
mentado Maravall, Suárez creyó que su nueva y frágil democracia no estaba preparada para acometer reformas económicas serias. (1993: 89).

El segundo rasgo distintivo aludía al ámbito de participación en el proceso de toma de decisiones. Específicamente, se les dio importantes roles a los principales partidos de la oposición en los procesos de toma de decisiones relativos a la nueva Constitución y a los Pactos de la Moncloa. Para alcanzar estos últimos acuerdos, se invitó a los líderes de los partidos socialista y comunista a la residencia del Primer Ministro (la Moncloa) para negociar cara a cara la adopción de una amplia variedad de políticas sociales y económicas. Los Pactos de la Moncloa representaron uno de los puntos cumbre de la spolítica del consenso, que finalizó tras la promulgación de la nueva Constitución democrática. Este proceso de toma de decisiones era la evidencia clara del cambio tras un pasado franquista, pero era también una excepción a los modelos de toma de decisiones que surgirían en los tres períodos posteriores.

Había varias razones por las cuales se adoptó este procedimiento ampliamente integrador. Sin duda, lo más importante (como se ha constatado en las entrevistas con los dos Primeros Ministros de la anterior UCD) era hacer que estos grupos de la oposición -que representaban los segmentos de la sociedad de la izquierda y/o de la clase trabajadora excluidos anteriormente- sintieran que eran parte del proceso democrático y que percibieran que tenían interés en su éxito. Se acepta universalmente (GUNTHER, 1992: esp. 70-75) que esta estrategia de inclusión fue un ingrediente clave en el éxito de "la política de consenso", y contribuyó en gran medida a la consolidación del nuevo régimen. Una segunda razón por la cual se adoptó este procedimiento fue que esta clase de "contratos sociales" neocorporativos estaba muy de moda en la Europa occidental en los 70, y también se correspondía con las preferencias personales y los estilos de comportamiento de los actores centrales dentro del Gobierno de la UCD. Las circunstancias apremiantes de la crisis económica también implicaban que se adoptarían las medidas extraordinarias, relativas a la cooperación entre una amplia gama de grupos, para evitar que la economía sufriera un deterioro posterior.

Debe apuntarse que este proceso de negociación interpartidista amplia fue un reflejo directo del gran cambio de circunstancias en las que los grupos anteriormente reprimidos poseían ahora legalmente recursos coercitivos. Esto se hizo bastante explícito en el texto de estos acuerdos: el Gobierno de la UCD se comprometió a acometer una serie de reformas de políticas progresivas y, a cambio, los sindicatos socialistas y comunistas contendrían su actividad huelguista (un mecanismo explícitamente coercitivo) y las demandas salariales excesivamente inflacionistas. Fue un proceso negociado cuya dinámica y poder de integración eran impensables bajo el régimen franquista.
Una vez que la nueva Constitución había entrado en vigor y terminó la transición a la democracia, finalizó esta variedad de toma de decisiones. Esto no quiere decir que las negociaciones neocorporativistas entre el Gobiemo, empresarios y sindicatos no tuvieran lugar. Se negociaron dos acuerdos de este estilo durante la segunda fase de toma de decisiones - un acuerdo relativamente modesto en 1979-, el Acuerdo Marco Interconfederal, entre la UGT (el sindicato socialista) y la CEOE (máxima organización que representaba a los empresarios), y un Acuerdo $\mathrm{Na}$ cional sobre el Empleo en cierta manera más ambicioso, que incluía un paquete algo mayor de compromisos y concesiones por parte del Gobierno, la UGT y Comisiones Obreras y la CEOE en 1981. Pero el foco principal y los objetivos últimos de estas negociaciones eran mucho más limitados que los compromisos de mayor alcance sobre políticas públicas incluidos en los Pactos de la Moncloa, e involucraban al Gobierno en las negociaciones con los sindicatos, más que con los partidos políicos de la oposición.

Las negociaciones interpartidistas durante la segunda fase de la toma de decisiones democrática (1979-1982) tuvieron lugar sobre una base regular, pero esto simplemente reflejó el hecho de que el Gobierno de la UCD carecía de una mayoría en el Congreso de los Diputados y necesitaba recoger votos adicionales para aprobar su legislación. En consecuencia, la UCD negociaría con otros partidos (más en concreto, con el grupo parlamentario catalán y, a veces, el PSOE) para conseguir su apoyo, haciendo cualesquiera concesiones de políticas públicas que fuesen necesarias para conseguir la aprobación de las leyes en las Cortes. Este proceso de construcción de coaliciones cambiantes ad boc se guió en gran medida por las normas "mayoritarias" del comportamiento parlamentario, más que de acuerdo con la lógica consensual o cuasiconsociacional que dominó el período anterior.

En otros aspectos, no había diferencias sustanciales entre la primera y segunda fase, o entre los procedimientos básicos de toma de decisiones de los Gobiernos de Suárez y Calvo Sotelo (ver Calvo Sotelo, 1990: $42-3$ y 67). Si bien había una gran implicación por parte de los actores políticos "centralesn en el establecimiento de las prioridades de las políticas públicas, tanto con Suárez como con Calvo Sotelo (en contraste con el régimen franquista), sin embargo, había algunas diferencias de estilo entre los dos. Suárez estuvo absorto casi completamente en cuestiones de "alta polítican, especialmente relacionadas con las tareas asociadas a completar la transición a un nuevo régimen (incluyendo las negociaciones con catalanes y vascos sobre sus respectivos Estatutos de Autonomía regional a mitad de 1979). Estaba muy poco interesado en los asuntos económicos y en el proceso presupuestario. En consecuencia, transfirió la mayor parte de la responsabilidad por esas políticas a un Vicepresidente. El primer Vicepresidente para Asuntos Económicos, Enrique Fuentes Quintana, ocupó su puesto por un período de 
tiempo demasiado breve (julio 1977 a febrero de 1978) como para institucionalizar este rol, pero su sucesor (de febrero de 1978 hasta septiembre de 1980), Fernando Abril Martorell, desempeñó un rol esencial en el establecimiento e implementación de las prioridades presupuestarias. Colaboró muy de cerca con el Ministro de Hacienda e inicialmente con el Ministro de Economía (los dos cargos se fundieron posteriormente en un único Ministerio de Economía y Hacienda) para desarrollar esta función. Abril, un amigo personal de Adolfo Suárez, consultaba frecuentemente con el Presidente del Gobierno durante este proceso. Por tanto, a diferencia de lo que ocurría bajo el régimen franquista (pero muy similar a los roles duales en la toma de decisiones del Presidente y el Primer Ministro en la Francia de la Quinta República), los dos líderes del Gobierno al más alto nivel estuvieron íntimamente involucrados en el establecimiento de las políticas maroeconómicas, del gasto y la imposición. El Vicepresidente desarrolló este papel de coordinación de las políticas públicas en calidad de presidente de la Comisión Delegada para Asuntos Económicos (comité selecto sobre asuntos económicos), entre cuyos miembros se incluían los Ministros de Economía y Hacienda, Industria, Transporte y Turismo, Agricultura, Obras Públicas y Vivienda, y Trabajo, y el Secretario de Estado para la Economía. Todas las cuestiones presupuestarias que no afectaban simplemente la distribución intradepartamental de fondos fueron discutidas por este comité selecto.

Las políticas públicas que traían consigo la aprobación de una nueva legislación o promulgación de Decretos-leyes también se discutieron dentro de la Comisión de Subsecretarios (compuesto por funcionarios de segundo orden de todos los Ministerios y presidido por el Ministro de la Presidencia del Gobierno), que tenía la potestad de introducir enmiendas menores en el texto. Si ningún Ministerio ponía objeciones al texto de la ley propuesta, se ponía en la .lista verde (indice verde), y se ratificaba en la reunión posterior del Consejo de Ministros sin debate. Por otra parte, si las deliberaciones en la Comisión de Subsecretarios no generaban un apoyo consensuado, el asunto se ponía en la alista roja. (indice rojo) para una discusión más en extenso en el Consejo de Ministros, donde el Primer Ministro resolvería la discusión en última instancia. Las deliberaciones sobre los asuntos económicos o presupuestarios por el Consejo de Ministros eran excepcionales; normalmente, el gabinete dedicaba las deliberaciones en sesión plenaria a cuestiones más puramente políticas. Y las discusiones presupuestarias nunca se resolvieron a través del voto en el Consejo; el mismo Primer Ministro decidiría entre las preferencias opuestas de sus ministros.

Las cuestiones de políticas públicas menos importantes se discutían, a iniciativa del Ministro pertinente, y se resolvían en la Comisión Delegada para Asuntos Económicos, dando por sentado que no había ningún desacuerdo sustancial y que el Vi- cepresidente del Gobierno apoyaba la propuesta. Si las discusiones surgían sobre tales propuestas, sin embargo, éstas se remitían al Consejo de Ministros para la resolución final. De nuevo, el Primer Ministro era el árbitro último en los conflictos interdepartamentales.

En todos los estadios de las deliberaciones sobre las propuestas relativas a los gastos o ingresos públicos, y en todas estas arenas de toma de decisiones, el Ministro de Hacienda ejerció una considerable influencia. Es importante reiterar, no obstante, que los frecuentes y cercanos contactos entre el Ministro que financia y el Vicepresidente ( $e$, indirectamente, el Presidente del Gobierno) diferenciaban claramente este proceso de la toma de decisiones económicas bajo el régimen anterior.

Cuando Abril fue sustituido como Vicepresidente en septiembre de 1980, fue reemplazado por Leopoldo Calvo Sotelo, que continuó desempeñando ese papel de coordinación y toma de decisiones hasta que llegó a ser Presidente del Gobierno cuatro meses más tarde. Sin embargo, Calvo Sotelo estaba tan interesado en los asuntos económicos y presupuestarios, que después de llegar a ser Presidente, continuó él mismo desempeñando este papel, antes que delegar su responsabilidad a un Vicepresidente. Dadas las otras muchas responsabilidades del Primer Ministro, el rol de coordinador de las políticas públicas presupuestarias (p. ej., aquélla desempeñada anteriormente por el Vicepresidente) se delegó al Ministro de Economía y Hacienda. No obstante, el Primer Ministro desempeñó el papel clave en el establecimiento de prioridades. Mientras que este cambio representó ciertamente un estilo de toma de decisiones diferente del de su inmediato predecesor, se hace más clara la aguda ruptura con respecto de la no implicación por parte de las figuras políticas centrales del régimen franquista.

La UCD como partido no jugó un papel directo en el establecimiento de prioridades presupuestarias. De hecho, las divisiones internas dentro del comité ejecutivo impidieron seguir el mismo curso sobre tales políticas. La ejecutiva del partido estaba preocupada por las luchas entre sus facciones y por temas no presupuestarios más importantes, tales como la entrada en la OTAN y la privatización de la televisión (Calvo Sotelo, 1990: 66). Esto no quiere decir que la UCD como partido no tuviera efecto sobre las prioridades de las políticas públicas. Como resultado del faccionalismo y la carencia de compromiso del partido como institución legítima (ver GUNTHER y HOPKIN, de próxima publicación), era necesario spagar continuamente a las diversas facciones "para librarse de ellas. recompensándolas con puestos ministeriales cuyas jurisdicciones se relacionaban más de cerca con sus preocupaciones principales. A los cristianos demócratas, por ejemplo, se les dio el control de Ministerios tales como Educación (que regulaba y subvencionaba el sector religioso de la educación), los liberales ocupaban canteras como el Ministerio de Cultura, y a los socialdemócratas (muchos de los cuales eran 
economistas) se les colocó a cargo de los Ministerios económicos. Esto tuvo las consecuencias desafortunadas de reforzar la fragmentación jurisdiccional que había sido heredada del régimen franquista, además de aumentar los intereses en conflicto entre las facciones.

Finalmente, el impacto de los grupos de interés fue bastante desigual y desinstitucionalizado. El papel más decisivo de los sindicatos tuvo lugar en el curso de la negociación de los pactos neocorporativistas con el Gobierno, como se ha señalado anteriormente. Pero no hubo un papel consultivo regular aparte de estas deliberaciones poco frecuentes. Y contrariamente a las habituales afirmaciones de la prensa del momento, no había un input significativo en el establecimiento de prioridades políticas de orden superior por parte de los denominados poderes fácti$\cos$ (p. ej., élites económicas, religiosas y militares). De hecho, las relaciones entre las grandes empresas y los bancos, por una parte, y los Gobiernos tanto de Suárez como de Calvo Sotelo, por otra, fueron muy antagónicas, como se ha señalado anteriormente, y los dos primeros ministros anteriores negaron inequívocamente en las entrevistas que los militares o religiosos hubieran influido en sus decisiones clave de alguna manera. En resumen, las élites militares, religiosas y empresariales, más que ejercer una poderosa influencia entre bastidores en el curso de las políticas públicas del Gobierno durante la era de la UCD, en cambio parecen haber funcionado como grupos que presionaban a los Ministros para anteponer sus intereses concretos y particulares y que se topaban con un Gobierno de la UCD que estaba adoptando políticas que a menudo desaprobaban.

Los procesos de toma de decisiones presupuestarias bajo los Gobiemos del PSOE durante la tercera fase (1982-89) fueron decididamente diferentes en varios sentidos de los de los anteriores Gobiemos de la UCD. Un cambio importante fue que la autoridad para formular e implementar una amplia gama de las políticas del Gobierno se había transferido a los gobiemos regionales de reciente creación. Al final de este período, alrededor del $20 \%$ del gasto público en España había sido realizado por los gobiernos regionales, y otro $12 \%$ por los gobiernos municipales. Esto contrasta con el Estado español altamente centralizado que precedió al proceso autonómico: en 1978, el 89\% del gasto total público estaba por completo bajo el control del Gobierno central. (Desafortunadamente, puesto que no se han acometido estudios de comportamiento del presupuesto regional hasta la fecha, esta importante dimensión de la toma de decisiones del Gobierno no puede discutirse aquí).

Con la llegada al poder del PSOE a finales de 1982, el papel clave del Vicepresidente del Gobierno en la toma de decisiones se alteró sustancialmente. El Vicepresidente Alfonso Guerra presidió la Comisión de Subsecretarios, que resolvía asuntos no controvertidos, y preparaba la agenda para el Consejo de Minis- tros, remitiendo a éste la resolución de importantes disputas interdepartamentales. Pero no desempeñó el mismo papel directo en el establecimiento de las prioridades del gasto como sus predecesores de la UCD. En vez de eso, las negociaciones bilaterales cruciales con los Ministros que efectuaban el gasto, que tenían lugar al final del ciclo presupuestario anual, fueron acometidas por el Ministro de Hacienda en solitario (más que en tándem con el Vicepresidente, como ocurría bajo los Gobiernos de la UCD). Por tanto, con los Gobiemos de González de 19821989, se incrementó, en gran medida, el poder del Ministro de Hacienda, y la función del Vicepresidente se redujo mayormente a la de servir de epolicía de tráfico. regulando el flujo de propuestas legislativas a través del proceso de toma de decisiones. Las habilidades personales y las tácticas negociadoras de Miguel Boyer y Carlos Solchaga fortalecieron además la autoridad del Ministerio de Hacienda. Se emplearon declaraciones alarmantes acerca del deteriorado estado de la economía acompañado de las tácticas negociadoras de recorte (en las cuales las concesiones previas hechas a los ministros que efectuaban el gasto les eran retiradas y sus partidas presupuestarias recortadas) para tratar de mantener bajo control el crecimiento del gasto. En general, los Ministros de Hacienda parecían ser más influyentes en el proceso presupuestario anual de lo que lo habían sido sus predecesores de la UCD. Este acrecentamiento del papel del Ministro de Hacienda no implicó, sin embargo, una vuelta a las prácticas de la era franquista.

Un rasgo de mayor importancia en los procesos presupuestarios del PSOE durante este período fue el papel dominante en el establecimiento de prioridades y la, a veces, significativamente decisiva intervención del Primer Ministro. Felipe González se involucraba mucho en el establecimiento de las prioridades generales al comienzo de cada ciclo presupuestario, y a menudo intervenía directamente al final. Cuando las discusiones entre el Ministro de Hacienda y los titulares de los departamentos que efectuaban el gasto no podían resolverse mediante negociaciones privadas o por la Comisión de Subsecretarios, se residenciaban en el Consejo de Ministros. En general, el mismo González resolvía finalmente estas disputas. A veces la intervención del Primer Ministro era extraordinariamente osada: como explicó un ex ministro socialista en una entrevista, un año, frustrado por la ausencia de consenso sobre el nuevo presupuesto, anunció al aturdido Consejo de Ministros: ‘jyo mismo voy a distribuir el $5 \%$ del presupuesto!. Esto era un acontecimiento excepcional, pero, en conjunto, el impacto acumulado de las intervenciones cada vez más incrementales pero frecuentes de González en el curso de más de una década le permitió tener una enorme influencia sobre las políticas de gasto e imposición fiscal del Estado español. En particular, la aparición de la educación y el desarrollo infraestructural como las máximas prioridades del Gobierno eran reflejo de sus propias preferencias personales en cuanto a políticas públicas. 
Una segunda característica distintiva de la toma de decisiones del PSOE era la influencia del partido. A menudo, en las disputas entre los departamentos que efectuaban el gasto y el Ministro de Hacienda, los compromisos programáticos del partido se invocaban con bastante éxito para garantizar fondos adicionales para un sector particular de la actividad del Gobierno. Además, el comité ejecutivo del partido discutía a veces las prioridades presupuestarias que iban surgiendo de las negociaciones dentro del Gobierno, y expresaba su preocupación porque se estaba reduciendo excesivamente el gasto en ciertas funciones. En la medida en que muchos Ministros del Gobierno (y lo que es más importante, el Presidente y el Vicepresidente del Gobierno) también eran miembros del comité ejecutivo del partido, los canales de comunicación entre el partido y los que tomaban las decisiones pertinentes eran numerosos y estaban abiertos. En general, la existencia de una ejecutiva del partido relativamente homogénea, que (a diferencia de la UCD dividida en facciones) fue capaz de alcanzar el consenso sobre aspectos claves de políticas públicas, supuso una ventaja importante para los ministros en sus batallas anuales con el Ministro de Hacienda. En el nivel agregado, los compromisos del partido relativos a las políticas públicas tuvieron un impacto significativo en la configuración de los resultados de políticas públicas.

Una tercera característica distintiva del presupuesto entre 1982 y 1989 fue que el PSOE no dependía del apoyo de otros partidos parlamentarios para aprobar su legislación. Por tanto, en contraste con las amplias consultas interpartidistas de la "política del consenso", y con los procedimientos de construcción de coaliciones cambiantes ad boc que caracterizaron la segunda fase, se adoptaron normas de toma de decisiones más mayoritarias. La sensación de estabilidad en el poder del Gobierno (basada en su enorme mayoría parlamentaria y la ausencia de una amenaza electoral verosímil en esa época representada por cualquier partido de la oposición), junto con el hecho de que no tenía que negociar o comprometerse con otros partidos parlamentarios, eran ventajas importantes que permitieron al partido adoptar políticas de restructuración económica impopulares y atrevidas, tales como el programa de reconversión industrial. Como reflejo de su considerable mayoría parlamentaria, el PSOE pudo aprobar casi todos sus proyectos de ley durante la legislatura de 1982: en contraste con la capacidad relativamente limitada del anterior Gobierno de la UCD para promulgar la legislación propuesta (207 de los 287 proyectos de ley que introdujo entre 1979 y 1982 se convirtieron en ley), 183 de las 200 propuestas legislativas del Gobierno del PSOE fueron aprobadas por las Cortes entre 1982 y 1986. En consecuencia, los input de los partidos de la oposición alcanzaron su nivel más bajo durante la legislatura de 1982-1986, cuando el PSOE tenía una enorme mayoría: durante este período sólo se promulgaron 13 proposiciones de ley introducidas en el Congreso por los partidos de la oposición y sólo una en el Senado ${ }^{16}$; esto se compara con las 33 y 6, respectivamente, durante la legislatura de 1979-1982 (LOPEZ GARRIDO y SUBIRATS, 1990: 40; ver también MaURER, 1995: y CAPO et al., 1990).

Esto no significaba, sin embargo, que la negociación interpartidista no tuviese lugar. MaURER concluye en su estudio (1995: 163-4) que sería un grave enror deducir de la infrecuencia con la que se introducían formalmente las enmiendas durante el proceso legislativo que otros partidos parlamentarios no tuvieron ningún input en la legislación durante este período. Continuando con la norma general de las negociaciones privadas entre las élites políticas que surgió primeramente durante la transición, pero que continuó caracterizando la toma de decisiones española hasta bien entrados los 90, los ministros del PSOE a menudo intentaron asegurarse el apoyo de otro partido a una propuesta antes de su sometimiento a las Cortes. Sin embargo, el motivo principal que hay detrás de estas discusiones interpartidistas informales, era indudablemente diferente de aquellas que sostenían las negociaciones paralelas a éstas durante el período de 1977-78 (cuando la colaboración era parte de la estrategia política para consolidar la nueva democracia) y entre 1979 y 1982 (cuando simplemente eran necesarias para conseguir votos adicionales para aprobar las propuestas). La razón fundamental más importante era el deseo de prepararse para el futuro cultivando una relación cordial y colaboradora con un partido que algún día podría servir como socio en una coalición. Como manifestó un ministro anterior en una entrevista: "Nosotros éramos conscientes de que no tendríamos una mayoría parlamentaria absoluta para siempre, y nos estábamos anticipando al día en que no tendríamos el apoyo de otro partido, o no estuviésemos ya en el poder. Esta razón fundamental condujo a acuerdos frecuentes con la coalición catalana centrista Convergència y Unió (que con el tiempo desempenó un papel clave en la toma de decisiones en la cuarta fase, especialmente después de 1993). Participantes menos frecuentes en tales discusiones eran los representantes parlamentarios del Partido Nacionalista Vasco, con los que de alguna manera era más difícil tratar, dadas sus posiciones más rígidas y conservadoras, especialmente cuando estaban en juego los temas Iglesia-Estado. Una segunda razón fundamental explica en gran medida algunas concesiones legislativas al principal partido de la oposición, Alianza Popular/Partido Popular. A veces se hicieron algunos ajustes en los contenidos de la legislación para demostrar a $\mathrm{AP} / \mathrm{PP}$ que se habían escuchado sus críticas y sugerencias. Con la incorporación de estas modificaciones en las propuestas se intentaba reducir la posibilidad de que el partido de la oposición considerara la legislación como totalmente inaceptable y, por tanto, si asumía el control del gobierno en algún momento en el fururo, daría completamente la vuelta a la legislación y la reemplazaría por un Derecho más partidista. No obstante, todas estas discusiones con AP/PP eran privadas y tenían lugar fuera de la arena parlamentaria. Con independencia de lo que se ha- 
bía dicho en estas discusiones privadas, AP mantuvo firmemente una actitud de oposición en el Parlamento, yendo a veces tan lejos como para cuestionar la constitucionalidad de las propuestas legislativas del Gobiemo mediante recursos ante el Tribunal Constitucional.

Como ocurría con la UCD (y, de hecho, con el General Franco), el Consejo de Ministros como colectivo no estableció prioridades de políticas públicas mediante el logro de un cierto consenso negociado, y nunca resolvió conflictos sobre asuntos presupuestarios mediante votaciones formales. En vez de eso, la resolución de los conflictos entre los Ministros de Hacienda y los diversos departamentos que efectuaban el gasto era más bien el producto de la intervención del Primer Ministro, tras alguna discusión en el Consejo. Otros ministros (aparte de los directamente implicados en la discusión) participarían alguna que otra vez en estas discusiones, pero, como sugerían las reglas de la lógica del presupuesto en base cero, sólo en muy raras ocasiones la petición de un ministro que efectuaba el gasto iba a ser apoyada de forma altruista por sus colegas. Como manifestó un ministro anterior:

-Lo que me sorprendió más cuando entré en el Gobierno fue lo rápidamente que los individuos modificaban la defensa de los presupuestos de sus propios ministerios. Podian haber hecho grandes discursos durante la campaña electoral sobre lo importante que era mejorar la educación o las autopistas, pero una vez que asumían sus responsabilidades como ministros, todo eso se olvidaba y se limitaban a los asuntos de sus propios departamentos.

Como reconocían que un incremento del gasto en los programas de otros departamentos podría exigir una reducción de sus propios presupuestos, raramente intervenían para apoyar a otros ministros en estas batallas. Como resultado de ello, el Consejo de Ministros no desempeñó un papel colectivo en la toma de decisiones.

También en congruencia con el presupuesto bajo la UCD (así como bajo el franquismo), los grupos de interés tenian solamente una influencia restringida y esporádica en las decisiones presupuestarias. Los ministros eran objeto de un lobbying intenso por la defensa de sus intereses particulares y precisos, pero con una excepción, las organizaciones secundarias fuera del Gobierno no tuvieron un impacto directo sobre las prioridades de gasto de orden superior del Gobiemo español. Esa excepción tuvo lugar en 1985, cuando, a cambio de su colaboración con el Gobierno y la CEOE en el acuerdo neocorporativista de 1985, el Acuerdo Económico y Social, se invitó a la UGT a participar (junto con la CEOE y el Gobierno) en la determinación de la distribución del 10\% del presupuesto del Estado en inversión. Aparte de este ejemplo, no se consultó a los sindicatos ni a otros grupos de interés y no tuvieron un impacto directo en el diseño básico de las prioridades presupuestarias del Estado. De hecho, el AES de 1985 fue el último de esos acuerdos neocorporativistas. A finales de los 80 , las relaciones entre el Gobierno del PSOE y los sindicatos se habían deteriorado hasta tal extremo que no estuvieron en absoluto dispuestos a participar en tales negociaciones (ver Maravall, 1993: 119), a pesar de los repetidos intentos del Gobierno por restaurar un diálogo neocorporativista. Debe señalarse que el final de tales acuerdos se corresponde con una tendencia europea occidental más amplia en la que los contratos sociales y otras medidas neocorporativistas se abandonaron como instrumentos de políticas públicas ${ }^{17}$.

La cuarta y última fase de la toma de decisiones que se discute aquí empezó en 1989. Mientras que algunos de sus rasgos distintivos empezaron a surgir ese año (con cambios en la composición del Gobiemo y con la pérdida de una mayoría absoluta en el Congreso de los Diputados [MAURER, 1995]), estas características llegaron a hacerse más patentes tras las elecciones de 1993, en la que la representación parlamentaria del PSOE descendió a 159 de los 350 escaños en el Congreso. La formación de un Gobiemo minoritario de un solo partido ese año significó que, al igual que con los Gobiemos de la UCD, se requería el apoyo legislativo de al menos otro partido para la aprobación de todas las propuestas.

En contraste con las prácticas de la UCD, que se basaban en coaliciones legislativas cuyos socios variaban según los temas, el PSOE alcanzó acuerdos amplios y explícitos, una vez al año, con el líder nacionalista catalán Jordi Pujol. A cambio del apoyo de los 17 diputados de CiU para el año siguiente, Pujol conseguiría compromisos relativos a una amplia gama de temas de políticas públicas. En términos de prioridades presupuestarias, éstos trataron, en gran medida, de imponer una mayor austeridad presupuestaria y la liberalización del mercado de trabajo, además de un aumento sustancial del flujo de recursos del Gobierno central a las diferentes Comunidades Autónomas regionales. La extensión del poder de Pujol sobre las políticas públicas del Gobierno fue tal que el influyente diario El País (de 11 de septiembre de 1994) se refirió a él como el Copresidente del Gobierno.

Un segundo conjunto de cambios que tuvo lugar durante este periodo aludía a los procesos de toma de decisiones dentro del gabinete. Junto a la sustitución de Alfonso Guerra como Vicepresidente del Gobierno por Narcís Serra, se produjo una vuelta a la mayor importancia del papel presupuestario del Vicepresidente. Mientras que Guerra se había estado preocupando por otros asuntos políticos, a Serra se le dio un papel más importante en el proceso de toma de decisiones presupuestarias. En 1994, esto incluía la responsabilidad de negociar con Pujol el próximo presupuesto. Este aumento del papel del Vicepresidente se acompañó también de un declinar general en la implicación directa de Felipe González en la formulación de estas políticas. Si esto era resultado de la fatiga después de más 
de una década como Primer Ministro, la preocupación por los cada vez más numerosos escándalos políticos, o la sustitución de una cohorte de antiguos amigos y colaboradores por recién llegados, parece que a mediados de los 90 González estaba siendo apartado cada vez más del control directo del Gobierno, que había detentado en la década precedente.

\section{Observaciones finales}

A la muerte de Franco en 1975, España era sorprendentemente diferente de otras sociedades europeas occidentales en muchos aspectos aparte de su régimen político autoritario y anacrónico. A pesar del rápido crecimiento económico de la década y media anterior, sus políticas públicas de gasto e imposición fiscal eran más parecidas a las del Tercer Mundo que a las de una sociedad industrializada moderna. He argumentado que, mientras que estos resultados anómalos de las políticas públicas representaban en parte los efectos residuales de la tardía industrialización, también deben considerarse como el producto directo de los constreñimientos impuestos sobre el proceso de las políticas públicas por el General Franco y su régimen. Hemos visto claramente que, una vez que se eliminaron esos constreñimientos como consecuencia de la transición a la democracia, España empezó a evolucionar rápidamente hacia modelos de actividad del sector público más típicamente europeos occidentales, para mejor o para peor. El sistema fiscal ineficiente, arcaico y regresivo, defendido tan tenazmente por la élite franquista, dio paso inmediatamente a uno que era más típico de las sociedades democráticas modernas. La infraestructura social y física provista por el Estado mejoró sustancialmente. Sólo con respecto a la provisión de algunos servicios de protección social, el Estado franquista había estado remotamente próximo a los Estados de bienestar social avanzados de la Europa occidental. Pero incluso en este sector, la desigualdad de la cobertura prestada por el sistema y los niveles extraordinariamente bajos de subvención estatal a los fondos de la Seguridad Social lo apartaban del resto del mundo industrializado. Aquí, también, al desmantelamiento del régimen franquista siguió un incremento masivo de las obligaciones presupuestarias del Estado. Casties (1995, y de próxima publicación) no sólo descubrió que España, inmediatamente después del comienzo del proceso democratizador, tenía sin duda la tasa más rápida de crecimiento del gasto de la Seguridad Social de cualquier país de la OCDE, sino que también su análisis multivariable de series temporales reveló que la mayor parte de este incremento se explicaba por una variable ficticia (dummy) que medía los efectos del cambio de régimen político. En resumen, la sustitución del régimen franquista por un sistema democrático hizo posible que las políticas públicas españolas se aproximasen a los niveles encontrados en el resto de la Europa occidental.

Los procesos de toma de decisiones gubernamentales, que tuvieron varias características extraordinarias bajo el régimen franquista, han venido también a parecerse a aquéllos encontrados en otros sistemas políticos europeos occidentales. Hemos observado algunas variaciones en el estilo de toma de decisiones de un período a otro: un Primer Ministro puede desempeñar un papel dominante y directo en el establecimiento de las prioridades de las políticas públicas, mientras que otro, preocupado por asuntos no presupuestarios, puede delegar su autoridad para la supervisión de estos procesos de elaboración de las políticas públicas; el papel de coordinación del Vicepresidente ha aparecido y desaparecido con sorprendente rapidez; el papel de los grupos de interés en el establecimiento de prioridades de orden superior ha variado considerablemente; y los partidos de la oposición han tenido diferentes niveles de input en el establecimiento de las prioridades de políticas públicas. Pero todos estos modelos cambiantes están dentro de una gama de variación encontrada en todos los sistemas políticos europeos occidentales. Todos los rasgos verdaderamente distintivos de la toma de decisiones franquista han desaparecido. Los líderes políticos principales ya no están interesados o implicados en el establecimiento de las prioridades de orden superior de las políticas públicas. Ya no se eliminan automáticamente ciertas opciones de políticas públicas, ni se excluyen completa y permanentemente a amplios sectores de la sociedad española del proceso de elaboración de las políticas públicas.

Sin duda, la modernización de la economía y la sociedad de España contribuyó a la expansión masiva de los servicios del Gobiemo (especialmente los servicios sociales), que comenzó a mediados de los 70. Los movimientos de población, los cambios demográficos, y las demandas de una economía industrial avanzada crearon la necesidad de una actividad del Gobierno nueva o más amplia, mientras que un incremento sustancial de la riqueza agregada hizo posible garantizar tales programas. Pero el cambio socioeconómico sólo proporciona, en el mejor de los casos, una explicación parcial. En términos de políticas públicas, pueden crearse vacíos funcionales que dan lugar a una respuesta en forma de programa de gobierno, y puede establecerse el potencial económico para que las políticas públicas den una respuesta importante. Sin embargo, España a mitad de los 70 revela claramente las limitaciones de los esfuerzos reduccionistas socioeconómicos para explicar fenómenos políticos complejos: el cambio social rápido había creado la necesidad. de servicios nuevos o más amplios, y el crecimiento económico había generado los recursos financieros potenciales para garantizar tales programas, pero, mientras Francisco Franco estuviese vivo, había obstáculos políticos insalvables para desarrollar pro- 
gramas que habrian guiado a España en la dirección del modelo europeo occidental.

En gran medida, los cambios en los procesos de elaboración de las políticas públicas iniciados en la mitad de los 70 , en la estructura de resultados de las políticas públicas, y en su impacto en la sociedad son atribuibles a un cambio de régimen político. Esto es más obvio con respecto a los cambios en los procesos de toma de decisiones. El aumento del sentido de la responsabilidad colectiva por las políticas públicas del Gobierno que resulta de la responsabilidad electoral es una fuerza poderosa para el cambio. Aunque esto se ha manifestado en la intervención cada vez mayor del Primer Ministro en el proceso de elaboración de las políticas públicas (con o sin la colaboración de un Vicepresidente), más que en el papel del Consejo de Ministros en la toma de decisiones colectivas, esto representa un alejamiento acusado respecto de la no implicación de Franco y su Primer Ministro (de facto o de iure), Luis Carrero Blanco, y de la transferencia del papel de coordinación de las principales políticas públicas a un ministro cuya primera preocupación era reducir el nivel de gasto -el Ministro de Hacien$\mathrm{da}$ - Otra fuerza importante para el cambio inherente al paso hacia un Gobierno democrático era la concesión de los erecursos coercitivos" legales a los grupos anteriormente privados de sus derechos civiles. En consecuencia, el derecho de huelga aumentó significativamente la capacidad de los sindicatos y sus partidos políticos aliados para influir en el diseño básico de las políticas públicas, a veces como producto de la negociación directa, cara a cara, con el Gobierno. Quizá lo más importante es que la democracia colocó en las manos del público en general el recurso coercitivo último, la capacidad para hacer a un lado al titular del departamento. Esto no sólo aumentó el sentido de la responsabilidad colectiva del Gobiemo por sus decisiones de políticas públicas (como se señaló anteriormente), sino que también institucionalizó un proceso de alicitación competitivan (BEer, 1965) entre el Gobierno y los partidos de la oposición por el apoyo electoral mayoritario. Al persuadir a los partidos para que formularan sus programas electorales que se dirigirian a un conjunto más amplio de votantes (o al menos una coalición mínima vencedora), este proceso de concurrencia competitiva electoral tuvo una función clave de agregación de intereses, de la que se carecía en gran medida bajo el régimen autoritario anterior.

Demostrar el impacto del cambio de régimen sobre los resultados de las políticas públicas, como mencioné en mis observaciones introductorias, a veces se complica por el hecho de que el tipo de régimen se corresponde muy a menudo con otros determinantes poderosos de los resultados de las políticas públicas. En el caso español, sin embargo, ha sido posible aislar el impacto de la política de la influencia potencialmente confusa del crecimiento económico, ya que el período de crecimien- to económico más rápido tuvo lugar entre 1960 y 1975 , antes de la transición a la democracia, mientras que la transición y la consolidación de la democracia tuvieron lugar durante un período de estancamiento económico. Como hemos visto, sólo la expansión incremental del sistema de la Seguridad Social (que, debido a su completa autonomía del Presupuesto del Estado, es anómalo) anterior a 1975 es compatible con la explicación socioeconómica del crecimiento del gasto público. El resto del Presupuesto del Estado de hecho disminuyó como porcentaje de PIB durante el periodo de crecimiento económico más rápido. Aunque uno podría sostener que el retraso de las políticas sociales a mediados de los 70 era en parte un efecto moratorio. de la tardía industrialización de España, la spistola humeante. simbolizada por las propuestas asesinas. de reforma fiscal de Franco en 1973, junto con los otros rasgos aberrantes de los procesos de toma de decisiones del régimen, muestran una evidencia clara y consistente del impacto evidente de las características del régimen político sobre una amplia gama de resultados de las políticas públicas.

Mientras el impacto más poderoso de la política sobre los procesos de elaboración de las políticas públicas y sus resultados implicaba el cambio de un régimen autoritario a uno democrático, este estudio también ha puesto de manifiesto los efectos de la incumbencia de los partidos. Aunque muchas de las diferencias entre las políticas públicas adoptadas por los Gobiemos de la UCD y PSOE eran el producto de unas circunstancias de toma de decisiones en gran medida diferentes, también podría verse alguna influencia de las predilecciones programáticas de los dos partidos. Mientras sus políticas monetarias restrictivas y el compromiso para llevar a cabo la reconversión industrial condujeron a algunos a acusar al PSOE de "neoliberalismo", ciertamente los indicios persistentes de sus raíces socialistas se manifestaron en su creencia de que el Gobierno tiene un importante papel que desempeñar en el desarrollo de la infraestructura social y física para el crecimiento económico. Esto no sólo condujo a los Gobiemos del PSOE a extender el sistema de educación y las redes de tren y autopistas con mucha más fuerza, sino que también fueron mucho más atrevidos que su predecesor de la UCD en hacer el sistema fiscal más progresivo y capaz de generar un volumen mayor de ingresos para el Estado.

En conjunto, sin embargo, estas diferencias partidistas son sorprendentemente pequeñas. De hecho, tanto la UCD como el PSOE estaban sometidos a una gran presión por parte de sus respectivas clientelas electorales (las élites empresariales y la iglesia, en el caso de la UCD, y los trabajadores organizados, con respecto al PSOE) para adoptar políticas públicas de acuerdo con sus respectivos intereses particulares. Las tensiones resultantes contribuyeron sustancialmente al colapso de la UCD y a la ruptura de las relaciones en otro tiempo cordiales entre el 
PSOE y su sindicato afiliado, la UGT. En parte, esta divergencia de una defensa más directa de los intereses de sus propios apoyos centrales es una manifestación de un síndrome mayor de relaciones débiles o inexistentes entre los partidos y los intereses organizados en España. Este modelo, a su vez, es en parte una consecuencia estructural de las estrategias del desarrollo del partido atrapalotodo (catch-all) que se abstenian de tener vínculos institucionalizados con asociaciones secundarias (ver GUNTHER, SAN y SHABAD, 1986: esp. 58-177), además de la debilidad generalizada de grupos de interés institucionalizados en la sociedad española (HEYwood, 1995: 242). Por tanto, no es sorprendente descubrir que la toma de decisiones en la España democrática no se amolda a las concepciones de los partidos fundamentalmente como vehículos para la representación de los intereses de la clientela minuciosamente definidos.

Desde una perspectiva diferente, sin embargo, la naturaleza atrapalotodo (catcb-all party) de los partidos españoles, junto con la dinámica del proceso electoral, han desempeñado papeles claves en la diferenciación entre los resultados y los procesos de elaboración de las políticas públicas de los dos regímenes. Como he argumentado, se confirió un carácter privilegiado a la articulación de los intereses particulares en los procedimientos de toma de decisiones y ello por la propia naturaleza del mismo régimen franquista, mientras que la función de agregación de intereses era extremadamente débil y sólo se desempeñaba im- plícitamente en el curso de las negociaciones bilaterales privadas entre los ministros del Gobierno. Esto dio lugar a un conjunto de resultados de políticas públicas altamente conservador que estaba muy en desacuerdo con las preferencias de la gran mayoría de los españoles ${ }^{18}$. Bajo el régimen democrático actual, en contraste con lo anterior, la debilidad de los vínculos clientela-partido, combinados con las estrategias electorales que maximizan la búsqueda del voto del centro, condujo a los Gobiernos de centro-derecha de la UCD a adoptar políticas públicas mucho más progresistas socialmente y al PSOE a adoptar políticas reguladoras y monetarias más neoliberales. de las que sus seguidores principales podrían haber preferido. Al adoptar tales políticas, los Gobiernos estaban respondiendo a los intereses y preferencias de un segmento mucho más heterogéneo y numeroso de la población española próximo al segmento centro-izquierda del espectro político, a expensas de los intereses particulares de sus citados apoyos principales.

El impacto global del cambio de régimen sobre las políticas públicas ha sido el de transformar a España de una sociedad cuyos procesos de elaboración de las políticas públicas y sus resultados tenían similitudes desafortunadas con aquellos propios de algunos países del Tercer Mundo en uno que encaja bien dentro de la principal corriente de las democracias occidentales opulentas. En resumen, podemos concluir inequívocamente que, de hecho, la política sí que importa.
Arículo traducido por Gemma Sánchez Rontomé.

- Este trabajo fue publicado con el útulo -The Impact of Regime Change on Public Policy: The Case of Spain, en Joumal Public Policy, 16, 2; 1996, pp. 157-201, editada por Cambridge University Press. Esta Revista agradece al autor y a la editorial su gentileza de autorizar la traducción y publicación de este aruiculo en nuestras páginas.

* Profesor de Ciencia Políica, Universidad del Estado de Ohio.

1 El estudio de la toma de decisiones durante el régimen de Franco se ha basado en más de 200 horas de entrevistas con 97 funcionarios de nivel medio y alto de la $\mathrm{Ad}$ ministración del Estado entre diciembre de 1973 y febrero de 1975. (Los detalles relativos a la muestra de entrevistados, además de los hallazgos de este estudio se han publicado en GUNTHER, 1980). A éstas siguieron entrevistas en profundidad en los 80 y 90 , con los decisores de políticas públicas situados en el nivel más alto del régimen democráuico. Me be atenido muy especialmente a las entrevistas con el anterior Subsecretario del Ministerio de Economía y Hacienda, Javier Moral, los anteriones Ministros José María Maravall, ínigo Cavero y José Pedro Pérez Lorca, y los Primeros Ministros anteriores Leopoldo Calvo Sotelo y Adolfo Suárez. Les estoy especialmente agradecido a Leopoldo Calvo Sotelo y José María Maravall, con los que no sólo tuve excelentes y agudas entrevistas, sino que también leyeron y comentaron borradores anteriores a este manuscrito, y a Edward Malefakis, Juan Linz y Carles Boix por sus comentarios y sugerencias.

' Fuentes: para España, Ministerio de Educación y Ciencia, 21; para otros países, WI. LENSKY, 1975.

"En 1964, por ejemplo, el gobiemo de Bélgica gastó el 7.1\% de su PIB en educación, el de los Paises Bajos el 7.0\%, el Reino Unido el 6.0\%, Suecia el $5.4 \%$, Italia el $5.3 \%$, Francia el $4.6 \%$, y Alemania occidental el $4.2 \%$ (Fuente: Ministerio de Educación y Ciencia, 174).
4 Fuentes: Penn World Tables. Release 5.6. El autor está agradecido a Adam Przeworski por suministrarme esos datos.

'En 1965, el porcentaje medio del PIB de la OCDE extraido de todos los impuestos excepto las contribuciones a la Seguridad Social era de $21.8 \%$. En torno a 1975, se había elevado a un $25.4 \%$. Por tanto, el nivel de imposición excluida la Seguridad Social de España cayó del 48\% de la media de la OCDE al $41 \%$ (Fuente: OCDE, Estadisticas de Ingresos, 1993: 76).

${ }^{6}$ Desafortunadamente, no ha habido estudios empíricos sobre los procesos de toma de decisión en la Seguridad Social durante el régimen de Franco.

' Para una argumentación mucho más detallada en apoyo de esta interpretación, ver GUNTHER, 1980.

${ }^{8}$ Usaré esta expresión abreviada para referime a las prioridades relativas dentro de los amplios sectores de la actividad gubernamental, como educación us defensa nacional us obras públicas, a diferencia de las prioridades intradepartamentales o de orden inferior entre programas dentro del mismo sector de actividad estatal.

${ }^{9}$ Para descripciones detalladas y análisis de los procesos presupuestarios en los Estados Unidos, Gran Bretaña, Francia y Japón, ver WILDAVSKY, 1984 y 1988; WILDAVSKY y BOSKIN, 1982; WLDAVSKY y HECLO, 1974; LORD, 1973; y CAMPBELL, 1977.

${ }^{10}$ Los disturbios laborales de 1956, por ejemplo, condujeron a un aumento del gasto a través del Ministerio de Trabajo de 380 millones de pesetas en 1955 a 2,668 millones para el año siguiente. Pero esa parida del Ministerio descendió a 712 millones de pesetas en 1957, y a 276 millones en 1958.

$"$ En esta instancia, la autoridad para establecer las prioridades fue reforzada por virtud de un vínculo personal entre el titular en esa posición, López Rodó, y el asociado más próximo de Franco, Luis Carrero Blanco. 
12 Casi la mitad de las industrias que tenian pérdidas bajo los auspicios del Instituto Nacional de Industria (el bolding establecido en 1941 por Francisco Franco, como parte de la estrategia económica autárquica de los 40 y 50 ) habian sido nacionalizados después de 1975. (Ver The Financial Times, 18 de enero de 1985, hoja extra, 6; y Maravall, 1995: 118).

${ }^{13}$ Fuentes: Memorias del Instituto Nacional de Previsión, 1967-1976; y Secretaria General para la Seguridad Social, -Informe económico-financiero, Proyecto de Presupruesto de Seguridad Social, 1995, citado en MOTA LÓPEZ, 1995.

${ }^{14}$ El ejemplo más notable de la innovación política en esta área fue la promulgación en 1986 de la Ley General de Sanidad, que estableció el principio de la cobertura universal por parte del sistema de sanidad nacional. Esto condujo a una extensión en la cobertura de un $85.7 \%$ de la población en 1982 a un $99.9 \%$ en 1992 (RODRfGuez $C_{A}$. BRERO, 1994: 1480; ver también ZALDfVAR y CASTELLS, 1992: 135).

1) Fuentes: Número de estudiantes universitarios en 1979 de Сово, 1994: 1126, y en 1993 de Anuario El Pais, 1995: 177; tasa de matriculacion de COBO, 1994: 1141. Un estudio (ZALDVAR y CASTELS, 1992: 131) concluyó que en 1989 (cuando las matriculaciones universitarias eran un $26 \%$ más bajas de lo que serian sólo cinco años más tar- de) únicamente los Paises Bajos tenian un porcentaje más alto de matriculación en bs universidades, mientras que ouros colocaban a Francia a la cabeza, por detante de España ese mismo año. MARAVAll (1995: 82) señaló que en 1989 la lasa de matriculación universitaria de España en tomo a un 32\% estaba sólo por debajo de la de Francia (37\%), pero por encima de las de Suecia (31\%) y Gian Bretaña (24\%). Otro estudio (EvGumA, 1994: 368), sin embargo, sitúa el nivel de matriculación universitaria de España en un 36\%. En contraste, en 195;, sólo el $6 \%$ de los españoles en la cohorte de edad universitaria se matricularon en instituciones de educación superior.

t El Senado es irrelevante en gran medida para el proceso de toma de decisiones. De hecho, su misma existencia en su forma acual es objeto hoy dí de ura considerable discusión (Vet LóPEZ GaRrido y SUBRRATS, 1990: 44).

"Ver Maravall, 1995: 226-7; Zaldivar y Castells: 86-88; PÉrez DInz: 38-40; MartiNEZ-ALIER Y ROCA, 1988: 44-49; FuQUER, GINER Y MORENo, 1990: 41.

18 Numerosas investigaciones, por ejemplo, han descubierto que los españoles están más a favor de la igualdad en la distribución de la renta, y de un rol activo de un Estado de bienestar social patemalista, de lo que lo están los ciudadanos de otras sociedades más industrializadas (ver, por ejemplo, BelrRÁv, 1990: 318).

\section{Bibliografia}

ALCADE, Julio (1988), El gasto público en la democracia espaniola. Los hechos. Papeles de Economia Espaniola, 37, pp. 2-17.

(1994), ·endencias macroeconómicas, en Salustiano del Campo, ed., Tendencias sociales en España (1960-1990), volumen I. Bilbao: Fundación BBV.

BeER, Samuel H. (1965), British Politics in the Colectivist Age. New York: Alfred A. Knopf.

BelTRín, Miguel (1990), •La Administración Pública y los funcionarios. En Giner, ed., España: Sociedad y Política.

Box, Carles (1994), Partisan Strategies and Supply-Side Policies in Advanced Nations, 1960-1990. Ph. D. Disertación, Universidad de Harvard.

BorREL, José (1985), •El gasto público en la crisis: Tendencias y estrategias. Papeles de Economia Española, 23, pp. 72.99.

CAMPBELL, John Creighton (1977), Contemporary Japanese Budget Politics. Berkeley: Universidad de California Press.

Calvo Sotelo, Leopoldo (1990), Memoria viva de la transición. Barcelona: Plaza y Janés/Cambio 16.

CAMPo, Salustiano (ed.) (1994), Tendencias sociales en España (1960-1990), volumen I. Bilbao: Fundación BBV.

Capo Giol, Jordi; Cotarelo, Ramón; López Garrddo, Diego y Subirats, Joan (1990), -By Consociationalism to a Majoritarian Parliamentary System: The Rise and Decline of the Spanish Cortes. En Ulrike Liebert y Maurizio Cotta, eds. Parliament and Democralic Consolidation in Soutbem Europe. Londres: Pinter.

CASTIES, Francis G. (1995), -Welfare State Development in Southern Europe. West European Politics, 18, pp. 291-313.

Social Security in Southem Europe: A Comparative Overview. En Richard Gunther, P. Nikiforos Diamandouros y Gianfranco Pasquino, The Changing Role of the State in the New Southern Europe. De próxima publicación.

Castles, Francis G. y Mckinlay, R.D. (1978), ·Public Welfare Provision, Scandinavia, and the Sheer Futility of the Sociological Approach to Politics. British Joumal of Political Science, 9, pp. 157-171.
Comisarfa del Plav de Desarrollo (1973), -La planificación de España: Su organización, procedimiento y metodología. Monografia presentada en la Conferencia Iberoamericana de Ministros de Planificación y Desarrollo, Madrid, Mayo 21-25.

Cutrught, Philips (1965), .Political Structure, Economic Development and National Social Security Programs, American Joumal of Sociology, 70, Marzo 537-551.

EvGuITA, Mariano F. (1994), •Educación general. En Del Campo, Tendencias Sociales en España.

Flaquer, Luis; GINer, Salvador y Morevo, Luis (1990), -La sociedad española en la encrucijada. En Salvador Giner, ed., España: Sociedad y Politica. Madrid: Espasa-Calpe.

Giner, Salvador, ed. (1990), España: Sociedad y Politica. Madrid: Espasa-Calpe.

Gonzrifz Catalá, Vicente y Vicente Merno, Ana (1985), Anälisis económico-financiero del sistema español de Seguridad Social. 1964-1985. Madrid: Ministerio de Trabajo.

GuiLÉn, Ana M. (1992), Social Policy in Spain: From Dictatorship to Democracy (1939-1982). En Eivind Kolberg (ed.), Social Policy in a Cbanging Europe. Frankfurt am Main: Campus.

GUNTHER, Richard (1980), Public Policy in a No-Party State: Spanish Planning and Budgeting in the Tuilight of the Franquist Era. Berkeley: Universidad de Califonia Press.

(1986), EEl colapso de UCD. En Juan J. Linz y José Ramón Montero, eds., Crisis y cambio: electores y partidos en la España de los años ocbenta. Madrid: Centro de Estudios Constitucionales.

(1992), Spain: The Very Model of the Modern Elite Settlement. En John Higley y Richard Gunther, Elites and Democratic Consolidation in Latin America and Southerm Europe. Cambridge y New York: Cambridge University Press.

Gunther, Richard; SAnI, Giacomo y Shabad, Goldie (1980), Spain After Franco: The Making of a Competitive Panty System. Berkeley y Londres: University of Califomia Press.

GUNIHER, Richard y HOPKN, Jonathan, A crisis of Institucionalization: The Collapse of the UCD. En Richard Gunther, Juan J. Linz y José Ramón Montero, eds., Political Parties. De próxima publicación. 
HEYwOOD, Paul (1995), The Govermment and Politics of Spain. New York: St. Martin's Press.

HoPKIV, Jonathan (1995), UCD: An Organizational Analysis. Ph. D. Disertación, European University Institute, Florencia, Italia.

Instituto nactonal de Prevision (1976), Memoria del Instituto Nacional de Previsión, 1976. Madrid.

KEY, V.O. (1951), Southem Politics in State and Nation. New York: Alfred A. Knopf.

IJNZ, Juan J. y DE MIGUEL, Amando (1968), .La élite funcionarial española ante la reforma administrativa. Sociologia de la Administración Priblica Española, Anales de Moral Social y Económica, 17. Madrid: Centro de Estudios Sociales de la Santa Cruz del Valle de los Caídos.

LÓPEZ GarRiDo, Diego y Subirats, Joan (1990), -El proceso de toma de decisiones legislativas: Las relaciones Gobiemo-Parlamento en España (1977-1986). Papers, 33, pp. 35-49.

LORD, Guy (1973), The French Budgetary Process. Berkeley: University of Califomia Press.

LUKAUSKas, Arvid (1992), The Political Economy of Financial Deregulation: The Case of Spain, Ph. D. Disertación, Universidad de Pennsylvania.

Maravall, José María (1991), What is left? Social Democratic Policies in Southem Europe. Working Paper 1992/36. Madrid: Instituto Juan March.

(1993), .Politics and Policy: Economic Reforms in Southern Europe. En Luiz Carlos Bresser Pereira, José Maria Maravall y Adam Przeworski, Economic Reforms in New Democracies: A Social-Democratic Approach. New York: Cambridge University Press.

Forthcoming. XX. En P. Nikiforos Diamandouros y Richard Gunther, eds., Demo cratic Politics in the New Southern Europe.

_ (1995), Los resuliados de la democracia. Madrid: Alianza Editorial.

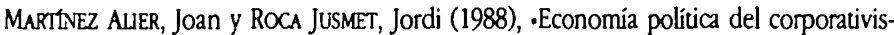
mo en el Estado español: Del franquismo al posfranquismo. Revista Española de Investigaciones Sociológicas, pp. 25-62, enero-marzo.

MAURER, Lynn M. (1995), Legislative-Executive Relations in a Newly Consolidated Democracy: The Case of Spain. Ph. D. Disertación, Ohio State University.

DE MIGuEl, Amando (1975), Sociología del franquismo. Barcelona: Editorial Euros.

MINISTERO DE EDUCACIÓN Y CIENCIA (1969), La educación en España: Bases para una politica educativa Madrid.

MOTA LÓPEZ, Rosalia (1995), .La seguridad social en España. Manuscrito no publicado. Madrid. Centro de Estudios Avanzados en Ciencias Sociales, Instituto Juan March.

Organizacón Para u CoOperactón y ei DesarRollo EConómico (1995), Revenue Statistics of OECD Member Countries, 1965-1994. Paris: OCDE.
PÉrEZ-Dinz, Víctor (1984), ·Políticas económicas y pautas sociales en la España de la transición: la doble cara del necorporatismo. En Linz, ed., España: un presente para el futuro.

Perona VRLareal, Diego (1972), La distribución de la carga tributaria en España. Madrid: Instituto de Estudios Fiscales.

RICHARDSON, Hatry W. y FERNÁNDEZ RodRiguez, Femando (1973), rRegional Development in Spain's trends Policies and Planning. Cambridge, Inglaterra, Manuscrito no publicado.

Rodriguez Cabrero, Gregorio (1994), ·Políticas de rentas. En Miguel Juárez, ed., V lnforme sociológico, vol. XX.

SchWarTz, Pedro (1976), PPolitics First: The Economy after Franco. Government and Opposition, 11, p. 2.

Secretaria General para ia Seguridad Social, Ministerio de Trabajo y Seguridad SoClal (1995), Proyecto de Presupuesto de la Seguridad Social, 1995.

SHARE, Donald (1986), .Four Years of Socialist Govemment in Spain: Tensions and Successes in the Consolidation of Party and Regime. Paper presented at Annual Meeting of the American Political Science Association, Washington, D.C., August, pp. 28 31.

SuBIRATS, Joan (1992), Un problema de estilo: La formación de politicas priblicas en España (Una aportación al análisis del sistema político español). Madrid: Centro de Estudios Constitucionales.

TAYIOR, Charles y HudSon, Michael (1972), World Handbook of Political and Social Indicators. New Haven: Yale University Press.

TEZaNos, José Félix (1984), Cambio social y modernización en la España actual. Revista Española de investigaciones sociológicas, octubre-diciembre.

_ (1990), Clases sociales. En Giner, España: Sociedad y Política.

VELARDE, Juan (1990), El tercer viraje de la Seguridad Social en España. Madrid: Instituto de Estudios Económicos.

WaGNER, Adolph (1892), Grundlegung der politischen Ökonomie. Leipzig: C.F. Winter. WILDASVKY, Aaron (1975), Budgeting (Boston: Little, Brown).

_ (1984), The Politics of the Budgetary Process, 4th ed. Boston: Litule, Brown.

(1988), The New Politics of the Budgetary Process. Glenview, IL: Scon, Foresman.

WILDAvSKY, Aaron y HeClo, Hugh (1974), The Private Government of Public Money: Community and Policy Inside British Politics. Berkeley: University of Califomia Press.

WILDAvSKY, Aaron y Boskin, Michael (1982), The Federal Budget: Economics and Politics. San Francisco: Transaction Books.

WILENSKY, Harold (1975), The Welfare State and Equality: Structural and Ideological Roots of Public Expenditures. Berkeley: Universisty of Califomia Press.

ZalDIvAR, Carlos Alonso y CASTELS, Manuel (1992), España: fin de siglo. Madrid: Alianza Editorial. 